\title{
An Efficient Reliability-Based Approach for Evaluating Safe Scaled Distance of Steel Columns under Dynamic Blast Loads
}

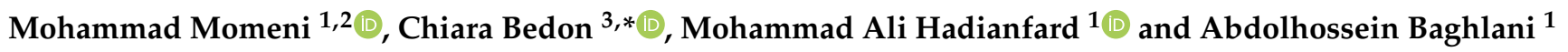 \\ 1 Department of Civil and Environmental Engineering, Shiraz University of Technology, \\ Shiraz 7155713876, Iran; m.momeni@sutech.ac.ir (M.M.); hadianfard@sutech.ac.ir (M.A.H.); \\ baghlani@sutech.ac.ir (A.B.) \\ 2 Department of Civil Engineering, Shahrekord Branch, Islamic Azad University, Shahrekord 88137333395, Iran \\ 3 Department of Engineering and Architecture, University of Trieste, 34127 Trieste, Italy \\ * Correspondence: chiara.bedon@dia.units.it
}

Citation: Momeni, M.; Bedon, C.; Hadianfard, M.A.; Baghlani, A. An Efficient Reliability-Based Approach for Evaluating Safe Scaled Distance of Steel Columns under Dynamic Blast Loads. Buildings 2021, 11, 606. https://doi.org/10.3390/ buildings11120606

Academic Editor: Paulo Santos

Received: 21 October 2021

Accepted: 29 November 2021

Published: 2 December 2021

Publisher's Note: MDPI stays neutral with regard to jurisdictional claims in published maps and institutional affiliations.

Copyright: (c) 2021 by the authors. Licensee MDPI, Basel, Switzerland. This article is an open access article distributed under the terms and conditions of the Creative Commons Attribution (CC BY) license (https:// creativecommons.org/licenses/by/ $4.0 /)$.

\begin{abstract}
Damage to building load-bearing members (especially columns) under explosions and impact are critical issues for structures, given that they may cause a progressive collapse and remarkably increase the number of potential victims. One of the best ways to deal with this issue is to provide values of safe protective distance (SPD) for the structural members to verify, so that the amount of damage (probability of exceedance low damage) cannot exceed a specified target. Such an approach takes the form of the so-called safe scaled distance (SSD), which can be calculated for general structural members but requires dedicated and expensive studies. This paper presents an improved calculation method, based on structural reliability analysis, to evaluate the minimum SSD for steel columns under dynamic blast loads. An explicit finite element (FE) approach is used with the Monte Carlo simulation (MCS) method to obtain the SSD, as a result of damage probability. The uncertainties associated with blast and material properties are considered using statistical distributions. A parametric study is thus carried out to obtain curves of probability of low damage for a range of $\mathrm{H}$-shaped steel columns with different size and boundaries. Finally, SSD values are detected and used as an extensive databank to propose a practical empirical formulation for evaluating the SSD of blast loaded steel columns with good level of accuracy and high calculation efficiency.
\end{abstract}

Keywords: safe protective distance; safe scaled distance; steel beam-column; dynamic blast load; reliability analysis; Monte Carlo simulation

\section{Introduction}

Crowded buildings such as schools, shopping venues, stadiums, transportation infrastructure and public locations are well-known attractive targets for terrorist attacks. The disruption of such places has irreversible consequences, including severe casualties and fatalities and negative impact on society [1]. There is a need to identify areas that may be potentially at risk and to take preventive measures to improve their safety and security. In this regard, securing the perimeter of structures or buildings using landscaping or barrier methods is one of the valid risk reduction options recommended in the literature for protecting buildings against terrorist attacks, including vehicle-borne improvised explosive devices [2]. These secure barriers must be installed the minimum required stand-off distance from a structure, in order to minimize the damage probability of primary structural elements and consequently the risk of progressive collapse. In order to design a blast-resistant building, the design engineer first has to determine blast loads on the building and its structural components. To determine the characteristics and intensity of blast loading, the parameters for explosive charge weight $(\mathrm{W})$ and stand-off distance $(\mathrm{R})$ must be necessarily known. There are several formulas and graphs that can be used to determine blast load parameters, as a function of the scaled distance parameter $(\mathrm{Z})$. The $\mathrm{Z}$ parameter, also known as $\mathrm{R} / \mathrm{W}^{1 / 3}$ [3], indicates that two charges with similar geometry, ambient 
conditions, explosive composition, but different size (weight) will produce self-similar blast waves as far as their distances $\mathrm{R}=\mathrm{Z} \times \mathrm{W}^{1 / 3}$ are identical. A much more complete discussion on features and applicability of the scaling law is given in [4]. In [5], the scaled distance parameter is used to assess the safety and resistance of structures under air blast loads. As an example, for un-strengthened buildings, an SSD of $4.46 \mathrm{~m} / \mathrm{kg}^{1 / 3}$ is specified from suffering a damage of "approaching to destruction" [5,6]. The SSD parameter, in this context, represents a guide to determine the explosive weight that can be used at a given distance, without exceeding the safe limit states of the structure (allowable support rotation values or damage index, for low damage). It should be noted that the SSD parameter is derived so that probability of failure is lower than an acceptance criterion. The probability of failure, as explained later in Section 3, is a function of capacity and demand called state function. In some cases, the state function can be expressed mathematically, but in most cases it does not have an explicit mathematical closed-form and must be defined by other methods such as FE analysis. When the state function is defined in mathematical form, it is possible to calculate the SSD parameter directly, otherwise an iteration-based method should be used to meet the acceptance criterion (Section 4). The SSD values presented in standards and regulations are usually obtained from blast tests on simple structural models and the effects of structural configuration or material properties are usually disregarded. As such, guidelines can be used for a quick safety assessment of structures, but do not provide clear damage scenarios [6]. Some studies have been performed to also investigate the SPD and SSD of structural elements under blast loads.

The blast performance assessment of structural systems is one of the critical issues for research. Accordingly, the need of empirical but accurate tolls in support of design optimization is an ongoing challenge. Among others, Byfield and Paramasivam [7] developed an iterative method to establish the minimum SSD of Reinforced Concrete (RC) columns for a given charge weight, column geometry and material. The iterative process must be repeated until the strength of the column is equal to the dynamic force in it. Thomas et al. [8] implemented MCS method for the reliability analysis of circular RC columns subjected to sequential vehicular impact and blast. Given that the stand-off distance has marked effects on reliability predictions, minimum SPD values have been proposed for selected configurations. Hadianfard and Malekpour [9] evaluated safe explosion distances of a steel column with IPBv220 and length of $3.6 \mathrm{~m}$ under different blast scenarios by utilizing the Single Degree of Freedom (SDOF) and FE methods via MCS method. Zhai et al. [10] investigated the blast effects on reticulated domes, proposing a method to determine the SSD based on the intersections of W-R charts and Pressure-Impulse (P-I) curves. Wu and Hao [6,11] numerically derived the SSD for masonry infilled RC frame structures. The presented SSD values for different damage levels ( $\mathrm{RC}$ frame collapse, side wall collapse, front wall collapse and excessive damage) were compared with the corresponding estimates by the US DoD [5] and ASCE [12] technical documents. A simple approximate method was proposed by Dorofeev for unconfined hydrogen explosions in three hypothetical obstructed areas with different congestion levels. Based on [13], a number of different safety distance relationships were stipulated depending upon the receptor under consideration, comprising storage distances, process building distances and public building and traffic distances.

To provide a robust background and comprehensive feedback for civil engineering applications, experimental and theoretical investigations on the effects of blast loads on steel structural members have been also reported in [14-17]. Bao and Li [18] focused on the residual axial capacity of square RC columns, while the study in [19] was dedicated to $\mathrm{H}$-section steel columns. A number of numerical investigations used equivalent SDOF systems and FE for primary members [16,20-32]. Besides, the uncertainty of input variables for blast load parameters and material properties (but also geometrical parameters and FE modelling errors [33]) can severely affect the predicted structural response. As such, probabilistic methods are preferred to support a more holistic risk-based approach [34-37]. Several studies have been focused on the reliability analysis of selected structures, such as RC buildings [38,39], steel structures [40], RC slabs [36,41], RC columns [35,42-44], RC 
wall panels [33,45], RC beams [46], composite walls [47], masonry walls [48], profiled wall structures [49], clamped aluminum plate [50] and steel columns [51,52], by considering the uncertainties of input variables related to material properties and blast load parameters. Stewart et al. explored the reliability analysis of structures under blast $[33,35,43,44]$ and supported the definition of a general framework for quantitative probabilistic risk assessment of structures subjected to blast [53-56]. Most of those studies have been developed based on MCS method along with SDOF, Multi Degree of Freedom (MDOF) and full 3D FE models. In [52], a methodology based on structural reliability analysis using MCS and explicit FE modelling (shell element formulation) was proposed for determining the damage probability of $\mathrm{H}$-shape steel columns (IPBv 200 section) under various blast scenarios. It was shown that the time required in a probabilistic analysis for iterations of 1000 and 300 can be expected to be about 100 and $30 \mathrm{~h}$. Such a run time may be acceptable for a single reliability analysis, but it is not suitable for SSD calculations that require a trial-and-error process with several reliability analyses. In this regard, a parametric analysis was performed in [57] to capture the effect of several FE modelling techniques (based on solid, shell or beam elements), blast intensity (medium and high levels) and supports (pinned or fixed ends), on damage evaluation assessment. It was proved that the beam formulations can offer good results for the calculation of the residual axial capacity of blast loaded steel columns, with high computational efficiency.

As mentioned above, recommending the minimum SSD is of high practical interest, especially for the design of structures in congested urban areas. Once SSD is known, the corresponding SPD can be easily calculated as a function of SSD and W. Although the blast dynamic behavior of structures has been largely investigated, the SSD of axially preloaded columns has been rarely considered and, to date, no comprehensive studies have been conducted. In this regard, this paper represents an effort toward the definition of a reliable and efficient methodology based on reliability analysis along with explicit FE approach (using beam element formulation) to determine the SPD and SSD for blast loaded steel columns. The proposed strategy, as shown, can be extended to different structural members (or assemblies) under the effect of a given explosion. In more detail, reliability analyses are carried out to obtain the curves of probability of low damage for a set of H-shape steel columns with different cross sections (IPB180 to IPB500), lengths (2.8, 3.2, 3.6 and $4.0 \mathrm{~m}$ ) and boundary conditions (pinned or fixed ends), under different explosive charge weights. Afterward, using the obtained curves of probability of low damage, the SSD are extracted for the selected configurations, to present a correlation between SSD and several input parameters (such as the explosive charge weight and the initial axial capacity of a given column) and derive some useful empirical formulas for practical design. An illustrative calculation example is finally discussed, in order to highlight the applicability of the proposed equations for calculating SSD and SPD of steel columns under blast loads.

\section{FE Numerical Analysis and Failure Assessment}

\subsection{Steel Columns}

A set of explicit FE models is developed using LS-DYNA software [58], to examine the blast loaded behavior of steel columns with different boundary conditions. As a reference, the limit pinned and fixed ends are considered. To characterize steel, MAT_PLASTIC_KINE MATIC material model is used. This constitutive model can adequately describe the isotropic and kinematic hardening plasticity, with the inclusion of strain rate effects based on the Cooper-Simonds relationship, that is [59-61]:

$$
\mathrm{DIF}=1+\left(\frac{\dot{\varepsilon}}{\mathrm{C}}\right)^{\frac{1}{\mathrm{P}}}
$$

where $\dot{\varepsilon}$ is the material strain rate, DIF is the dynamic increase factor and C and P are constant coefficients that were set to 40.4 and 5 for mild steel [61,62]. The stress-strain curve provided by MAT_PLASTIC_KINEMATIC material model is shown in Figure 1, 
where $\mathrm{L}_{0}$ and $\mathrm{L}_{1}$ are undeformed and deformed lengths of uniaxial tension specimen, respectively. Furthermore, $\mathrm{E}_{\mathrm{s}}, \mathrm{F}_{\mathrm{y}}, \mathrm{E}_{\mathrm{t}}, \sigma_{\mathrm{t}}$ and $\varepsilon_{\mathrm{t}}$ are the modulus of elasticity, yield stress, the slope of the bilinear stress strain curve in strain hardening region, true stress and true strain, respectively. Furthermore, kinematic, isotropic, or a combination of kinematic and isotropic hardening may be specified by varying $\beta^{\prime}$ between 0 and 1 as shown in Figure 1 [58].

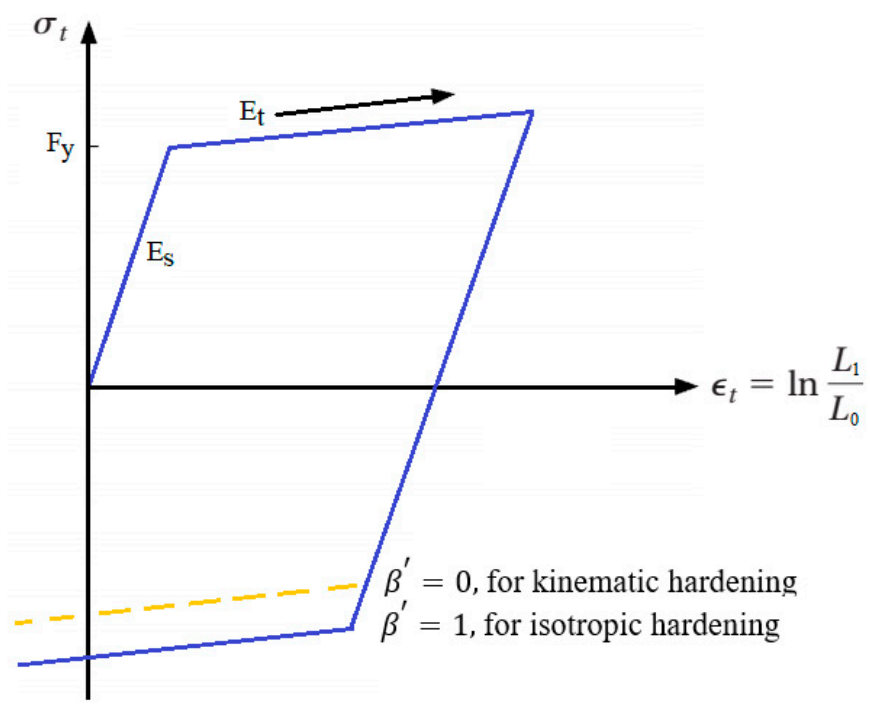

Figure 1. Stress-strain curve of MAT_PLASTIC_KINEMATIC model used for steel material [58].

It should be noted that strain hardening was not considered in this study and the value of $E_{t}$ was set to zero $\left(E_{t}=0\right)$. Such a choice was derived from earlier preliminary sensitivity studies where the results showed that strain hardening has no significant effect on residual axial capacity of a steel column [63]. For sake of conciseness, the aforementioned results are not included in the discussion herein reported.

The Hughes-Liu beam element formulation is used for the FE modelling of the selected steel columns $[57,64]$. There is an integration refinement factor in Hughes-Liu beam element formulation to determine integration points throughout a cross section. The number of integration points can vary depending on the desired accuracy required. A greater number of integration points can also more accurately represent the structural response. In this study $\mathrm{k}$ was set to $5(\mathrm{k}=5)$ following carried out sensitivity analyses that are not presented in the discussion herein for sake of brevity. A schematic drawing of the typical FE modelling of steel columns (as columns of a building (not columns of a boundary wall)) with $\mathrm{H}$-shape cross section and $\mathrm{k}=2$ is shown in Figure 2.

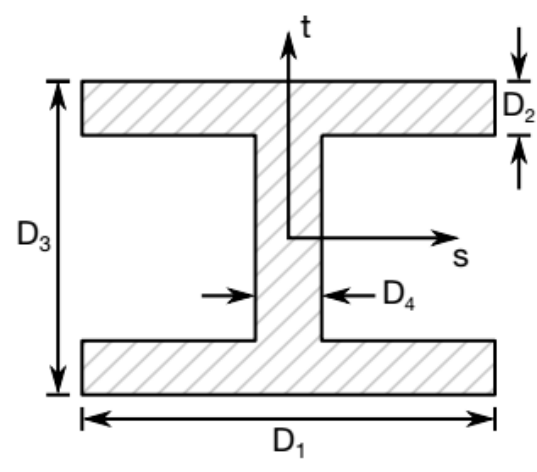

(a)

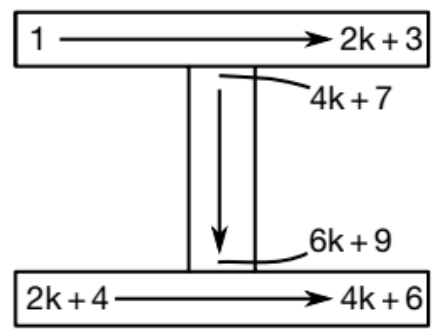

(b)

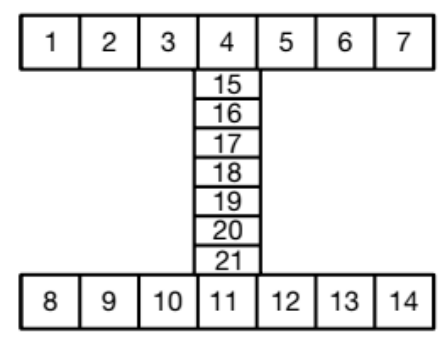

(c)

Figure 2. FE numerical modelling of $\mathrm{H}$-section steel column with Hughes-Liu beam elements: (a) cross section geometry; (b) integration point numbering; (c) section example for $\mathrm{k}=2$. 
Although the use of beam elements is notoriously deficient for simulating the effects of local buckling phenomena or shear damage mechanisms induced by blast loads, this choice can significantly improve the calculation efficiency of simulations (compared to shell and solid elements) when the global behavior prediction prevails on local behaviors. This advantage is further appreciated when the time reduction is a relevant issue, like in the case of reliability analysis.

\subsection{Nature of Blast Loading}

The magnitude of blast waves due to terrorist attacks can be generally classified in the number of explosive packs (portable by humans) and different types of used vehicles (such as automobiles, vans and trucks), based on the amount of $\mathrm{W}$ and the distance of detonation $\mathrm{R}[52,65]$.

In this research study, three types of surface burst explosive packs with 55, 275 and $555 \mathrm{~kg}$ of trinitrotoluene (TNT) are considered and can be reasonably assumed to be carried by an automobile, a van or a truck, respectively. The stand-off distance is also considered to modify in each blast scenario, in order to find the minimum required SPD, using the reliability analysis. It should be noted that human-made explosions generally occur on the vicinity of the ground surface. Due to this closeness, an immediate interaction initiates between the blast wave and the ground, which forms the hemispherical surface burst [66]. The incident waves are quickly reflected from the ground surface and lead to higher pressure values [67]. Based on [38,52,66,68-70], the parameters of the hemispherical surface burst (reflected pressure $\left(\mathrm{P}_{\mathrm{r}}\right)$ and the positive time duration $\left.\left(t_{d}\right)\right)$ can be defined using the conventional relationships for free air burst, by replacing $W$ with the effective charge weight $\left(\mathrm{W}_{\text {eff }}=1.8 \times \mathrm{W}\right)$. Finally, the blast load time history is defined based on the calculated surface burst parameters and is considered as a simplified equivalent triangular pulse, for all the FE modelled configurations. For the sake of conciseness and to avoid lengthening, no major details about definition of time history of blast loading are reported in this paper. More details can be found in [52,57].

\subsection{Damage Evaluation Assessment Based on Damage Index Criterion}

To numerically assess the expected damage of blast loaded steel columns after explosion, the damage index (DI) based on residual axial carrying capacity is taken into account in this study. According to Shi et al. [25], this index is given by:

$$
\mathrm{DI}=1-\frac{\mathrm{P}_{\text {residual }}}{\mathrm{P}_{\text {initial }}}
$$

where $P_{\text {residual }}$ is the post-blast residual axial capacity of the damaged column and $P_{\text {initial }}$ is the maximum axial load-carrying capacity of the undamaged column. The degrees of damage are thus categorized into four levels [25], namely corresponding to:

(a) $\mathrm{DI}=0-0.2$ low damage;

(b) $\mathrm{DI}=0.2-0.5$ medium damage;

(c) $\mathrm{DI}=0.5-0.8$ high damage;

(d) $\mathrm{DI}=0.8-1.0$ collapse.

It should be noted that for vertical load bearing components belonging to high-class buildings that are sensitive to lateral deformations and must be designed for maximum lateral ductility ratio 1 , no relevant damage is allowed and consequently DI must be selected in such a way that this limitation is satisfied. From a computational point of view, several calculation steps must be generally carried out to find the expected $P_{\text {residual }}$ value. The sequence of required steps, however, is not reported in this paper for the sake of conciseness. Additional details can be found in [52,57]. In blast-resistant design of structures, it is often stated that the damage caused in a structure due to blast loads would be reduced if the structure is well designed against seismic loadings. This is not true in all cases and it should not be assumed that a structure designed to withstand seismic 
loads is sufficient to resist the prescribed blast loading or prevent subsequent progressive collapse. Despite the similarities between seismic and blast loadings, the global response of buildings subjected to blast loading is not usually critical. In the other words, for a structure that is affected by an explosion, only its critical members (i.e., closer to detonation) are individually assessed and designed by means of different methods (SDOF and FE models) and damage criteria (support rotation and damage index), while for building structures under the effects of earthquake loadings, the global deformations (inter-story drifts) must be evaluated based on the desired performance level (life safety) as the most important response parameter [71,72]. In the design of structures under seismic and blast loading, the desirable features of design - that is, the provision for ductility in member response and increasing the ability to redistribute extreme loads to lesser-loaded elements—must be satisfied.

\section{Random Variables and Reliability Analysis Using MCS}

\subsection{Random Variables}

The variability of blast loading parameters is one of the key variables of the problem explored herein. A number of documents $[34,36,73]$ have reported constant coefficient of variation $(\mathrm{COV})$ values for the variability of blast loads at various scaled distances. On the other hand, the observed statistics obtained from blast tests and empirical formulations confirm the basic variability. To overcome this major limit, additional studies were performed in [35,37,73]. Among others, the proposals by Hao et al. [35] and Netherton and Stewart [37] are of general application and thus often used in the reliability analysis of blast loaded structures. Although the cited strategies are different, the shared feature is the blast load variability, which is expressed in terms of $Z$. Furthermore, the same strategies are validated for a wide range of scaled distance values $\left(0.24 \mathrm{~m} / \mathrm{kg}^{1 / 3} \leq \mathrm{Z} \leq 40 \mathrm{~m} / \mathrm{kg}^{1 / 3}\right.$ in [35] and $0.59 \mathrm{~m} / \mathrm{kg}^{1 / 3} \leq \mathrm{Z} \leq 40 \mathrm{~m} / \mathrm{kg}^{1 / 3}$ in [37]). As a final result of the formulations provided in [35] and [37], for a blast scenario (with specified charge weight and stand-off distance) the mean, standard deviation $(\sigma)$ and COV of wave parameters can be estimated as a function of $Z$. In this paper, $P_{r}$ and $t_{d}$ are selected as random variables for blast loading. It is also assumed that the uncertainties are defined based on [35], that is:

$$
\begin{aligned}
& \log P_{r(\text { mean })}=3.651-3.018 \times \log Z+0.1967 \times(\log Z)^{2}+0.8873 \times(\log Z)^{3} \\
& -0.3795 \times(\log Z)^{4} \\
& \log \sigma_{P_{\mathrm{r}}}=3.03-3.533 \times \log Z+0.4534 \times(\log Z)^{2}+0.3248 \times(\log Z)^{3} \\
& +0.07896 \times(\log Z)^{4} \\
& \log \mathrm{COV}_{\mathrm{P}_{\mathrm{r}}}=-0.6239-0.5726 \times \log \mathrm{Z}+0.3203 \times(\log \mathrm{Z})^{2}-0.3538 \times(\log \mathrm{Z})^{3} \\
& +0.2973 \times(\log Z)^{4} \\
& \begin{aligned}
\log \left(\frac{\mathrm{t}_{\mathrm{d}(\mathrm{mean})}}{\mathrm{w}^{1 / 3}}\right)= & -0.00307+1.2186 \times \log Z-0.5207 \times(\log Z)^{2}-0.2835 \times(\log Z)^{3} \\
& +0.2132 \times(\log Z)^{4}
\end{aligned} \\
& \begin{aligned}
\log \sigma_{t_{d} / w^{1 / 3}}= & -0.8433+1.0982 \times \log Z-0.8127 \times(\log Z)^{2}+0.4214 \times(\log Z)^{3} \\
& -0.1046 \times(\log Z)^{4}
\end{aligned} \\
& \begin{aligned}
\log \operatorname{COV}_{\left(\mathrm{t}_{\mathrm{d}} / \mathrm{w}^{1 / 3}\right)}= & -0.8411-0.1186 \times \log \mathrm{Z}-0.2868 \times(\log \mathrm{Z})^{2}+0.6955 \times(\log \mathrm{Z})^{3} \\
& -0.3141 \times(\log \mathrm{Z})^{4}
\end{aligned}
\end{aligned}
$$

Equations (3)-(8), in more detail, represent the statistical characteristics (mean, $\sigma$ and COV) of the $P_{r}$ and $t_{d}$ variables, as a function of $Z$, in the range of $0.24 \mathrm{~m} / \mathrm{kg}^{1 / 3} \leq Z \leq 40 \mathrm{~m} / \mathrm{kg}^{1 / 3}$. It should be noted that the $\log$ in these equations is the logarithm to the base 10 . As reported in [35], the proposed formulas are valid only for an open field explosion and large enough flat reflection surface. For a complex explosion scenario, such as an explosion in a complex city environment, more significant variations are expected because of blast wave interactions with surrounding structures. 
It should be noted that $t_{d}$ is the positive time duration of an idealized triangular blast loading history with sufficient accuracy instead an exponentially decayed loading history of a real explosion. The assumption of using triangular pressure-time history for blast loading originates from past research studies, such as $[35,37,38,42,43,55,74-79]$. There, the variation of the waveform coefficient for the positive pressure phase has been generally disregarded for the reliability analysis, due to lack of information. This issue depends on blast load databanks that have been used to propose analytical formulas to calculate the variation of blast load parameters as functions of scaled-distance. Among others, the parameter corresponding to the waveform coefficient has been considered probabilistic in [48,73], but the intended scaled distance was set between 1.62 and $2.78 \mathrm{~m} / \mathrm{kg}^{1 / 3}$, and an explicit relation was not presented for the calculation of statistical properties (i.e., mean and standard deviation) of the waveform coefficient based on scaled distance. Although the linear assumption of blast load imposes some unwanted approximation in the problem [35], such an assumption might cause an error up to $10 \%$ for the final results. In this paper, following former dedicated research $[35,37,38,42,43,55,74-79]$, a linear function is thus used to define the input blast.

Normal probability density function (PDF) is used for all input random parameters including loading parameters $\left(\mathrm{P}_{\mathrm{r}}\right.$ and $\left.\mathrm{t}_{\mathrm{d}}\right)$ and steel material properties $\left(\mathrm{F}_{\mathrm{y}}\right.$ and $\left.\mathrm{E}_{\mathrm{s}}\right)$, see Table 1 [35,42,80-82].

Table 1. Statistical properties of input random variables.

\begin{tabular}{ccccc}
\hline Random Variable & Mean & $\boldsymbol{\sigma}$ & COV & PDF \\
\hline $\mathrm{P}_{\mathrm{r}}$ & Equation (3) & Equation (4) & Equation (5) & Normal \\
$\mathrm{t}_{\mathrm{d}}$ & Equation (6) & Equation (7) & Equation (8) & Normal \\
$\mathrm{F}_{\mathrm{y}}$ & $240 \times 1.15 \mathrm{MPa}$ & $16.56 \mathrm{MPa}$ & 0.06 & Normal \\
$\mathrm{E}_{\mathrm{s}}$ & $210 \mathrm{GPa}$ & $8.40 \mathrm{GPa}$ & 0.04 & Normal \\
\hline
\end{tabular}

\subsection{MCS Method}

The MCS method is a well-known technique for estimating statistical properties of structural systems under stochastic uncertainties of input parameters $[83,84]$ and is used in this paper to carry out the reliability analyses. MCS is one of the simplest and relatively most accurate methods which provides a feasible way to determine the reliability index, where the limit state function is more complicated. Most of the literature studies on the reliability of structures under blast loading have been performed using MCS. The probability of failure based on MCS equals to $P_{f}=N_{f} / N$, where $N$ is the number of total simulations and $\mathrm{N}_{\mathrm{f}}$ is the number of trials for which limit state function, $\mathrm{g}(\mathbf{X})=r-q$, falls in the failure region or has negative value. In the definition of the state function, $\mathbf{X}$ is the vector of input random variables, $\mathrm{r}$ is the capacity or resistance, $\mathrm{q}$ is the demand or loading. The probability of failure can also be written as follows:

$$
\mathrm{P}_{\mathrm{f}}=\mathrm{P}[\mathrm{g}(\mathbf{X}) \leq 0]=\int_{\mathrm{g}(\mathbf{X}) \leq 0} \mathrm{f}_{\mathbf{X}}(\mathbf{X}) \mathrm{d} \mathbf{X}=\frac{\sum_{i=1}^{\mathrm{N}} \mathrm{I}_{\mathrm{F}}\left(\mathbf{X}_{\mathbf{i}}\right)}{\mathrm{N}}
$$

where $f_{X}(X)$ is the joint probability density function and $I_{F}$ is the failure indicator which equals 1 if $g(\mathbf{X}) \leq 0$ and 0 if $g(\mathbf{X})>0$.

The accuracy and precision of MCS in damage estimation directly depends on the $\mathrm{N}$ value. The higher the $\mathrm{N}$ value, the more precise the MCS. On the other hand, by increasing the number of simulations, the computational effort is also increased, which is the main disadvantage of the MCS method. In this regard, there are many procedures in the literature to find the minimum number of iterations required for MCS for a certain level of accuracy. The equation proposed by Broding et al. [85] is taken into account in this paper:

$$
N>\frac{-\ln \left(1-C_{L}\right)}{P_{f}}
$$


where $\mathrm{N}$ is the minimum number of required random samples, $\mathrm{P}_{\mathrm{f}}$ is the probability of failure and $C_{L}$ is the confidence level. In this paper, the value $N=300$ is taken into account for reliability analyses, which corresponds to $95 \%$ confidence $\left(C_{L}=0.95\right)$ and 0.99 reliability $\left(\mathrm{P}_{\mathrm{f}}=0.01\right)$.

\section{Methodology of Calculating SSD Using Reliability}

\subsection{SSD Definition}

SPD is defined as the minimum required stand-off distance where the probability of low damage based on Equation (2) is at least 95\% [86-88] or the damage probability is lower than an acceptance criterion $5 \%$. Figure 3 shows schematically an instance of probability of low damage diagram for a given charge weight, based on stand-off distance, that can be obtained from the results of reliability analysis for any blast loaded member. The concept in Figure 3 is shown for the specific case of probability of low damage $95 \%$. The philosophy is that the structure object of analysis is examined for different blast scenarios (under constant charge weight and a variable stand-off value) and the probability of low damage in each case is calculated and drawn in Figure 3. In the other words, each point in Figure 3 corresponds to probability of low damage for the selected configuration under a blast scenario.

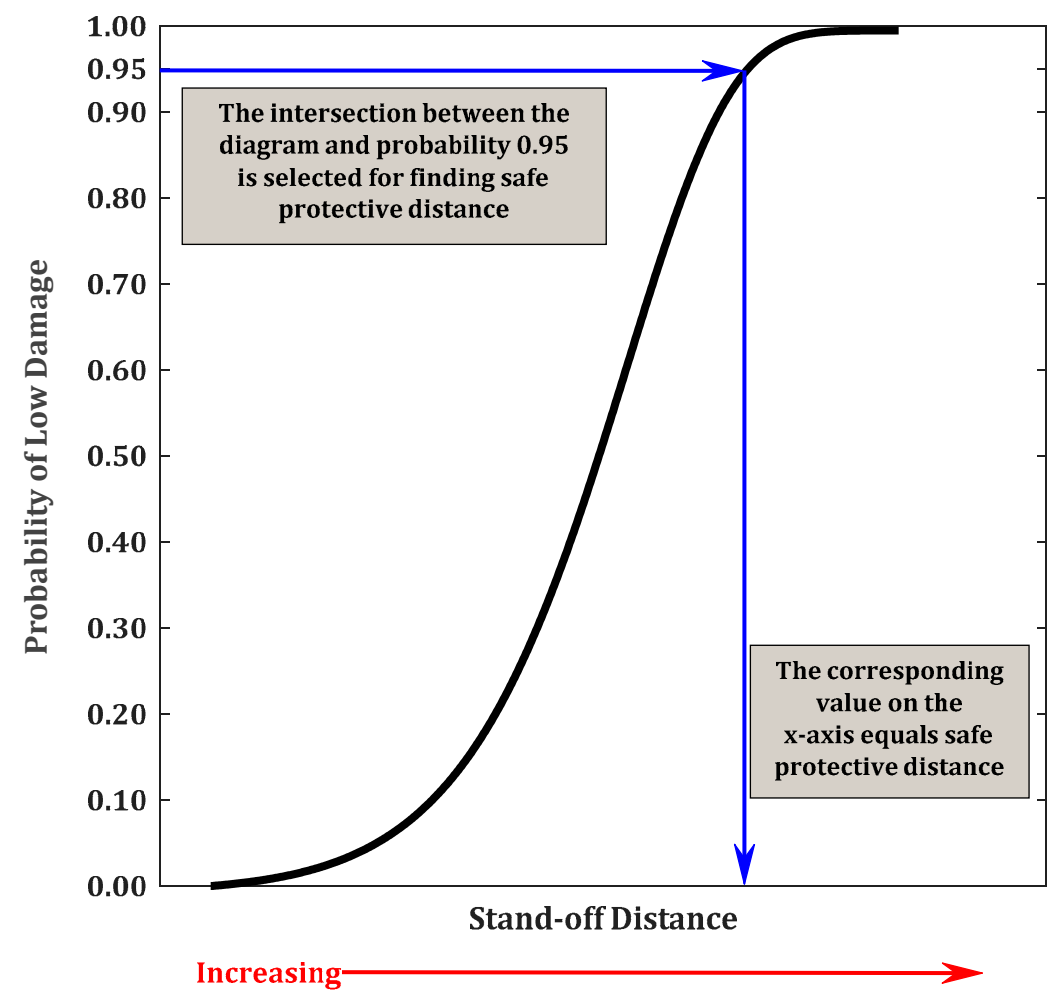

Figure 3. The concept of calculating SPD.

The desired output is obtained by a complete probabilistic analysis using MCS with 300 different simulations. The final result agrees with Figure 3 and is the basis for the SPD determination. This is in fact calculated as the stand-off distance corresponding to the intersection point between the diagram in Figure 3 and the probability of low damage 0.95. Once the SPD is known, the SSD can be easily determined, given that SSD $=S P D / W^{1 / 3}$.

\subsection{Application of Reliability Analysis Based on MCS in Calculating SSD}

Key steps to perform the SSD by implementing the concept of reliability analysis with MCS method and FE method (based on LS-Dyna software simulations) are summarized in this section. The full calculation process takes advantage of a set of LS-PrePost, MATLAB, LS-DYNA and C\# coding for each FE model, thus importing the models into LS-DYNA 
and extracting and post-processing the results of interest. As shown in Figure 4, the general procedure can be basically described as follows:

1. Definition of boundary conditions, section properties and length for the examined steel column.

2. Generation of the initial LS-DYNA model (input file) for the considered steel column. At this stage, hypothetical (average) values are used for input random parameters. The same values are then updated in the following calculation steps, based on the real values of generated samples, for each random parameter. The aim of step 2 is only to create a . $\mathrm{k}$ file format for the column that will be object of the probabilistic analysis.

3. Selection of a blast scenario, by defining corresponding values for charge weight and stand-off distance.

4. Calculation of the mean values and standard deviations for the input random variables. In this paper, the attention is focused on blast load parameters $\left(P_{r}\right.$ and $\left.t_{d}\right)$ and material properties ( $\mathrm{F}_{\mathrm{y}}$ and $\left.\mathrm{E}_{\mathrm{s}}\right)$, according to Table 1 .

5. Choice of appropriate probability density functions for the selected input random variables.

6. Generation of random variables (MATLAB code) according to the selected PDF (step 5).

7. Update of the initially generated LS-DYNA model (input file, see step 2), for the number of generated random variables (step 6), using MATLAB.

8. Analysis of all the FE models (by automatically running LS-Dyna software with C\# coding) and extracting all the damage indices (MATLAB).

9. Derivation of histogram, PDF and Cumulative Distribution Function (CDF) for the calculated DI (from step 8).

10. Calculation of the probability of low damage, or P[DI $\leq 0.2]$.

11. And in conclusion, a double check must be necessarily carried out, given that:

(a) If the probability of low damage from step 10 is approximately $95 \%$, the selected stand-off distance (step 3) coincides with SPD and consequently the required SSD can be calculated.

(b) Otherwise, if the probability of low damage is less or more than $95 \%$, the selected stand-off distance (step 3) must be increased or decreased, respectively. The full algorithm must be thus repeated (from step 3), until the probability of low damage reaches $95 \%$.

\subsection{Verification of Reliability Analysis Based on MCS Using Beam Element Formulation}

In order to verify the current MCS results based on beam element formulation, major outcomes from the reliability analyses presented in [52] are compared in this study. In more detail, the numerical results of two loading cases (Case 1 and Case 2) are considered, as obtained for a steel column with section type IPBv200, nominal length of $3.6 \mathrm{~m}$ and pinned ends. The column from [52] is made of ST37 steel, with density of $7850 \mathrm{~kg} / \mathrm{m}^{3}$. Yield strength, elastic modulus, Poisson's ratio and failure strain are set equal to $240 \mathrm{MPa}$, $210 \mathrm{GPa}, 0.3$ and 0.2 respectively. In Case 1 , the column is subjected to $\mathrm{W}=55 \mathrm{~kg}$ of TNT and $\mathrm{R}=6 \mathrm{~m}$. In Case 2, the explosive charge weight and the stand-off distance are set to $55 \mathrm{~kg}$ and $8 \mathrm{~m}$. For both configurations, the number of simulations is set to 300 . The comparison of past [52] and current numerical results is shown in Figure 5a,b, for Cases 1 and 2, respectively, in terms of CDFs for DI. 


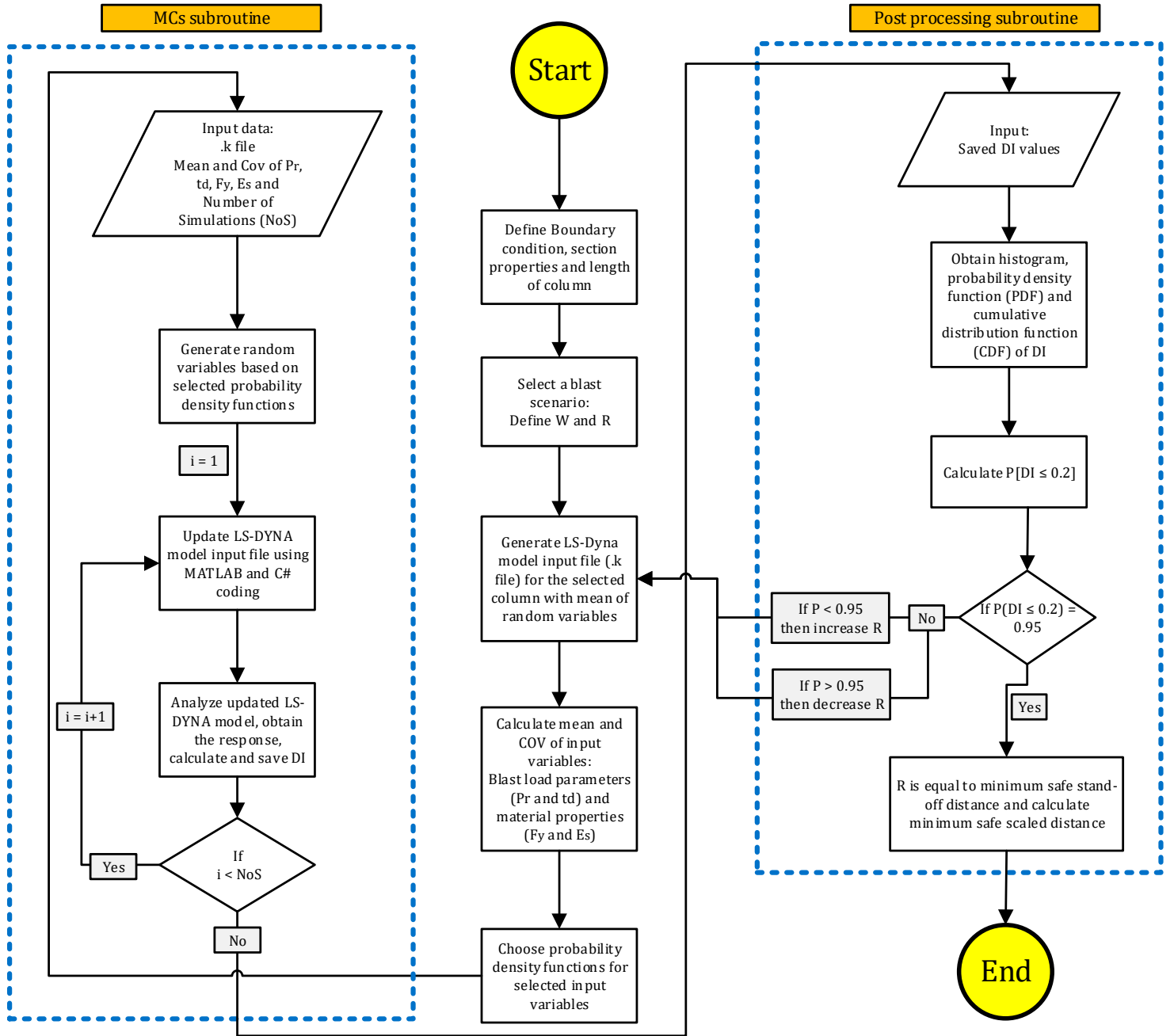

Figure 4. Procedures for SSD derivation based on structural reliability approach.

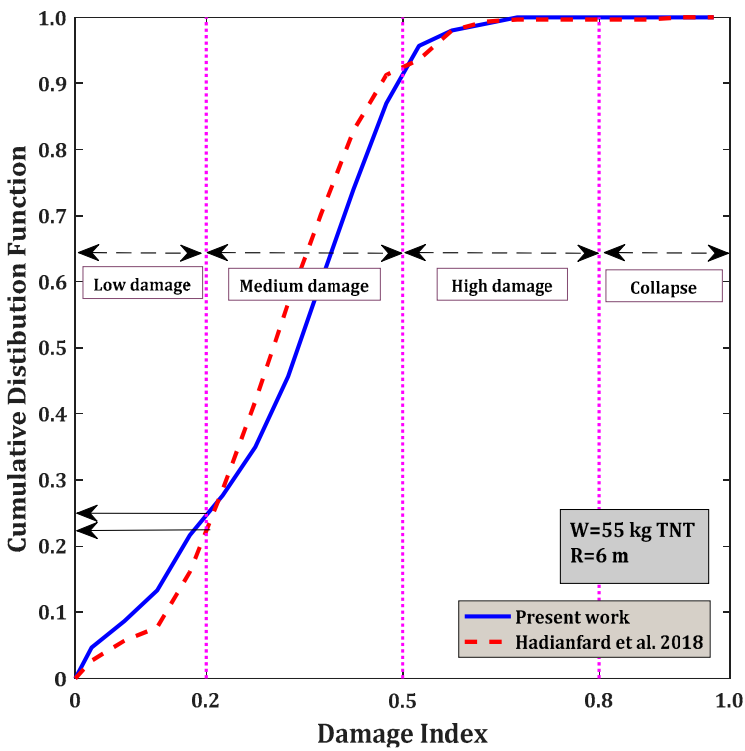

(a) Case 1

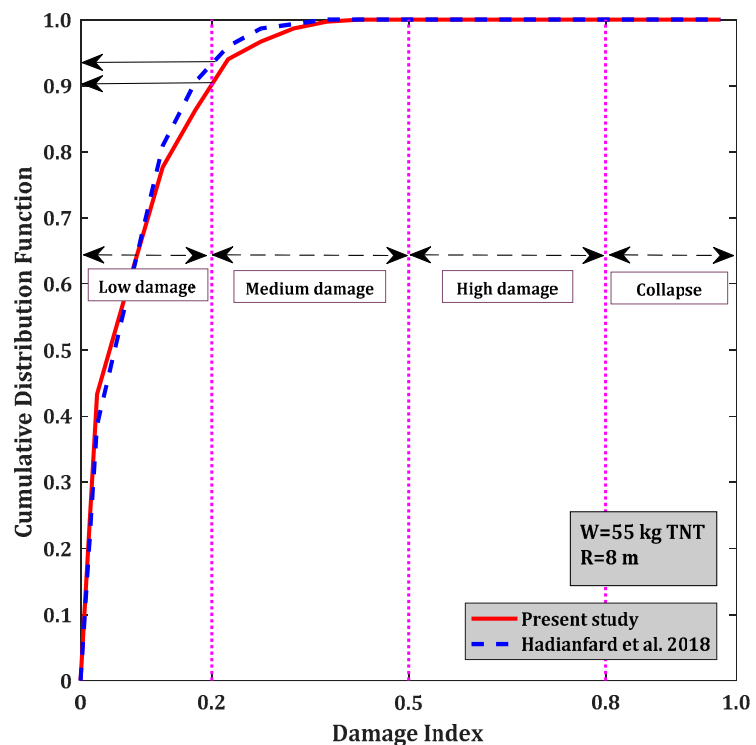

(b) Case 2

Figure 5. Comparison of the results of MCS based on beam (present study) and shell element types [52] for CDFs of DI: (a) Case 1; (b) Case 2. 
Based on Figure 5a,b, it can be clearly noticed that there is a rather close correlation between the collected results, even in the presence of different accuracy levels for the FE models in use (beam and shell elements, respectively). For Case 1, according to Figure 5a, the probabilities of low damage ( $\mathrm{DI}<0.2)$ are found to be 0.25 (present study) and 0.22 [52], with a scatter of $12 \%$. In Case 2, see Figure $5 b$, the probabilities of low damage (DI $<0.2$ ) are calculated at 0.90 (present study) and 0.93 [52], respectively, with a $3.22 \%$ scatter that further confirms the good agreement between the compared MCS results. In order to better clarify the performance of beam elements in probabilistic analysis, the required analysis durations for reliability analyses of the so-called Case 1 with beam and shell element types are thus presented in this paper. For beam elements, the typical required time was approximately $0.90 \mathrm{~h}$ for $300 \mathrm{MCS}$ iterations. For shell elements [52], the required time was in the order of $30 \mathrm{~h}$ for the same number of iterations (that is, 33.33 times higher), which shows that implementing beam elements speeds up the procedure, especially in finding SPD and SSD values which need many separate reliability analyses.

\subsection{Selected Columns}

Given the potential of beam element formulation, a set of $\mathrm{H}$-section steel columns with different geometrical properties in cross sections (IPB180 to IPB500) and lengths (2.8, $3.2,3.6$ and $4.0 \mathrm{~m}$ ) are considered in the FE parametric investigation. The reference crosssectional parameters are shown in Table 2, where $A_{g}$ is the cross-sectional area, $\mathrm{I}_{\mathrm{x}}$ is the moment of inertia about the strong axis ( $\mathrm{x}$-axis), $\mathrm{I}_{\mathrm{y}}$ is the moment of inertia about the weak axis (y-axis).

Table 2. Geometrical properties of selected H-sections for parametric FE simulations.

\begin{tabular}{|c|c|c|c|c|c|c|c|c|}
\hline \multirow[b]{2}{*}{ Identification } & \multicolumn{7}{|c|}{ Section Properties } & $\begin{array}{l}\mathbf{y} \\
\mathrm{I}\end{array}$ \\
\hline & $\mathrm{b}(\mathrm{mm})$ & $\mathrm{h}(\mathrm{mm})$ & $\mathrm{s}(\mathrm{mm})$ & $\mathrm{t}(\mathrm{mm})$ & $A_{g}\left(\mathrm{~cm}^{2}\right)$ & $\mathrm{I}_{\mathrm{X}}\left(\mathrm{cm}^{4}\right)$ & $\mathrm{I}_{\mathrm{y}}\left(\mathrm{cm}^{4}\right)$ & $\pi$ \\
\hline IPB 180 & 180 & 180 & 8.5 & 14.0 & 65.3 & 3831 & 1363 & \\
\hline IPB 220 & 220 & 220 & 9.5 & 16.0 & 91.0 & 8091 & 2843 & $\mathrm{~h}$ \\
\hline IPB 260 & 260 & 260 & 10.0 & 17.5 & 118.4 & 14,920 & 5135 & i \\
\hline IPB 300 & 300 & 300 & 11.0 & 19.0 & 149.1 & 25,170 & 8563 & i: \\
\hline IPB 340 & 300 & 340 & 12.0 & 21.5 & 170.9 & 36,660 & 9690 & $\frac{1}{1}$ \\
\hline IPB 400 & 300 & 400 & 13.5 & 24.0 & 197.8 & 57,680 & 10,820 & k \\
\hline IPB 500 & 300 & 500 & 14.5 & 28.0 & 238.6 & 107,200 & 12,620 & Reference cross section \\
\hline
\end{tabular}

\section{Results and Discussions}

\subsection{Curves of Probability of Low Damage}

The curves of probability of low damage are obtained in this paper for all the steel sections presented in Table 2 via reliability analysis, for both the pinned and fixed ends under different blast scenarios (with TNT charges of 55, 275 and $555 \mathrm{~kg}$ ). For example, Figure $6 \mathrm{a}-\mathrm{c}$ illustrate the numerical curves for IPB220 with pinned ends under explosive charge weights of 55, 275 and $555 \mathrm{~kg}$, respectively. Each plot corresponds to a column with a specified length and explosive charge. Furthermore, it consists of some observed points that are obtained from reliability analyses. Each observed point and its probability of low damage is in fact the result of a reliability analysis based on the MCS method with 300 simulations. In total, 15,900 simulations were performed to extract Figure 6a-c, indicating the high amount of computational effort, which was around $47.4 \mathrm{~h}$. Additionally, the normal CDFs have been fitted to the observed points for each case related to a specified column length, to convey a better understanding of presented concepts in Section 4 and also calculating the probability of low damage for points other than the observed points, if necessary. Given that the stand-off distance corresponding to the $95 \%$ probability of low damage is considered for finding safe distance (see Figure 4), then the fitting operation was used to find the stand-off distance corresponding to exactly $95 \%$ probability of low damage. In this case, lower tails are not important and will not affect the calculation and extraction of SPD and SSD. 


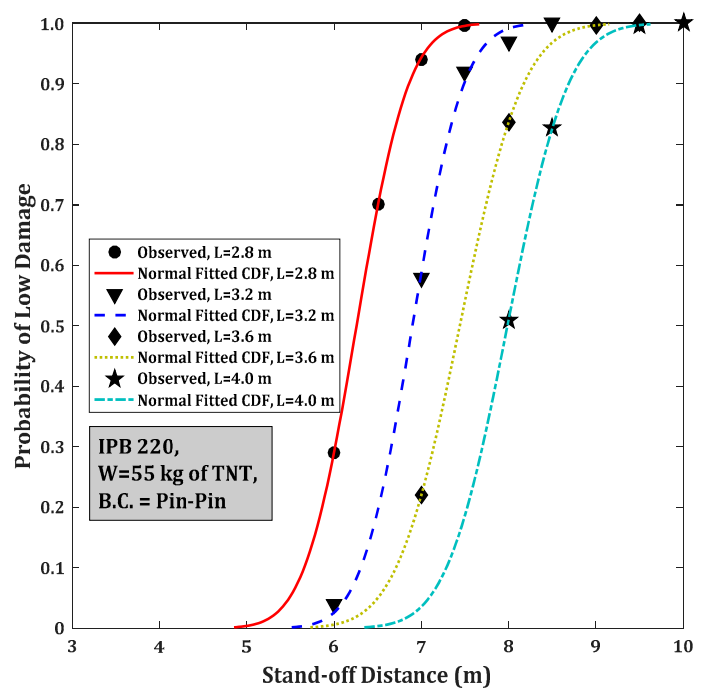

(a)

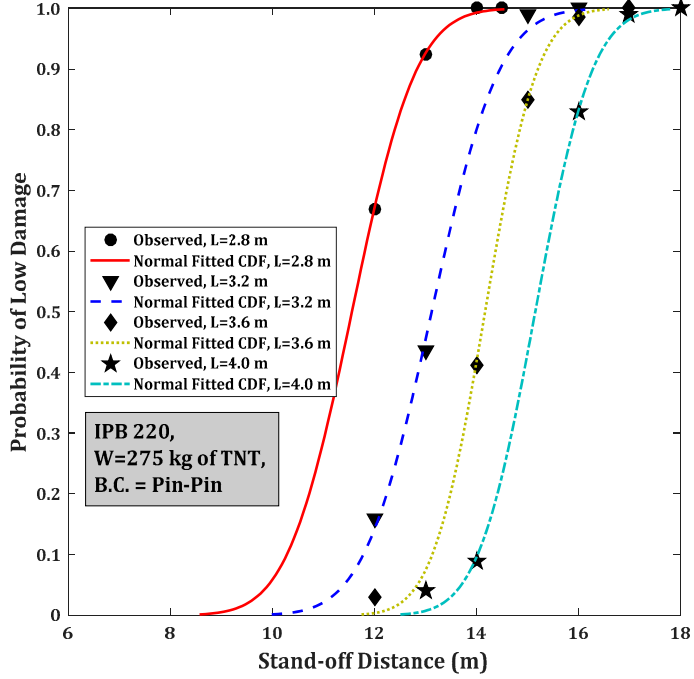

(b)

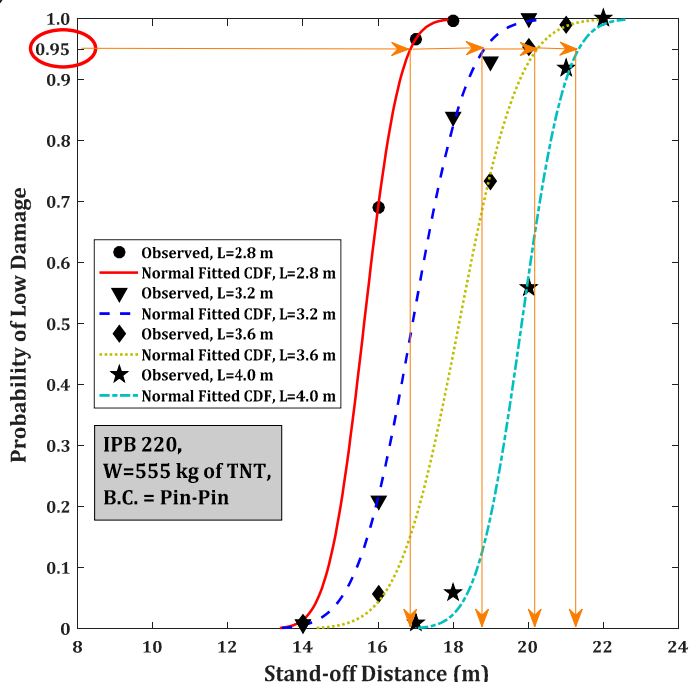

(c)

Figure 6. Curves of probability of low damage for IPB220 with pinned ends and different lengths subjected to: (a) 55, (b) 275 and (c) $555 \mathrm{~kg}$ of TNT.

According to Figure $6 \mathrm{c}$, the SPD value for IPB220 with pinned ends and $3.6 \mathrm{~m}$ of length, subjected to $555 \mathrm{~kg}$ of TNT, is approximately calculated as $20.2 \mathrm{~m}$ by considering the $95 \%$ probability of low damage as a criterion and using orange arrows connected to normal fitted CDF for $\mathrm{L}=3.6 \mathrm{~m}$ which eventually shows the value of SPD on the horizontal axis. As can be estimated from the figure, by changing the criterion from $95 \%$ to $99 \%$, the SPD increases to $21.0 \mathrm{~m}$. The important aspect, in this regard, is that the exclusive calculation of the SPD value for a column is not a sufficient way to provide protection against catastrophic events or major releases. In other words, finding the SPD value of $21.0 \mathrm{~m}$ by selecting $99 \%$ probability of low damage instead of $20.2 \mathrm{~m}$ (with $95 \%$ probability) does not mean that the safety of the examined steel column (or generally the whole structure) is ensured at this distance, without considering additional special arrangements. As such, the SPD values can be thus used as a valuable guidance to design and provide special arrangements around the building (such as appropriate access control and security guards), so as to reduce the frequency and/or the possible consequences to an acceptable level. The reliable prediction of adequate distances or separation zones around the building is thus one of the fundamental considerations for safe layout and can be designed according to SPD values. In some cases, it is worth mentioning that providing SPD for a structure to protect from all possible events is not practicable and this is especially the case in urban places, 
due to the lack of sufficient space between buildings and access roads. The assessment of the frequency of the expected event and its potential consequences is thus necessary to understand which risks can be reasonably mitigated by an SPD. For cases in which the obtained SPD value is too large, of course, additional mitigating or prevention measures should be considered. In a nutshell, the $95 \%$ criterion is internationally recognized to represent a rational choice for finding practical SPD that causes no serious damage for the structure (if special arrangements are provided) and the designer's judgment along with SPD values should lead to better decisions for ensuring safety of the structure under such events.

Similarly, Figure 7a-c present the curves of probability of low damage for IPB220 with fixed ends, subjected to explosive charge weights 55,275 and $555 \mathrm{~kg}$, respectively. As also explained in Section 4, using the obtained curves, the required SPD and the corresponding SSD can be calculated for each column by using orange arrows connected to each fitted curve. For instance, as Figure $6 \mathrm{c}$ reveals, the SPD values for IPB220 with different column lengths $(2.8,3.2,3.6$ and $4.0 \mathrm{~m})$ and pinned ends are calculated in 16.9, 18.8, 20.2 and $21.2 \mathrm{~m}$, respectively. Consequently, the SSD for lengths 2.8, 3.2, 3.6 and $4.0 \mathrm{~m}$ (and an explosive charge weight of $555 \mathrm{~kg}$ of TNT) are $2.06,2.29,2.46$ and $2.58 \mathrm{~m} / \mathrm{kg}^{1 / 3}$, respectively.

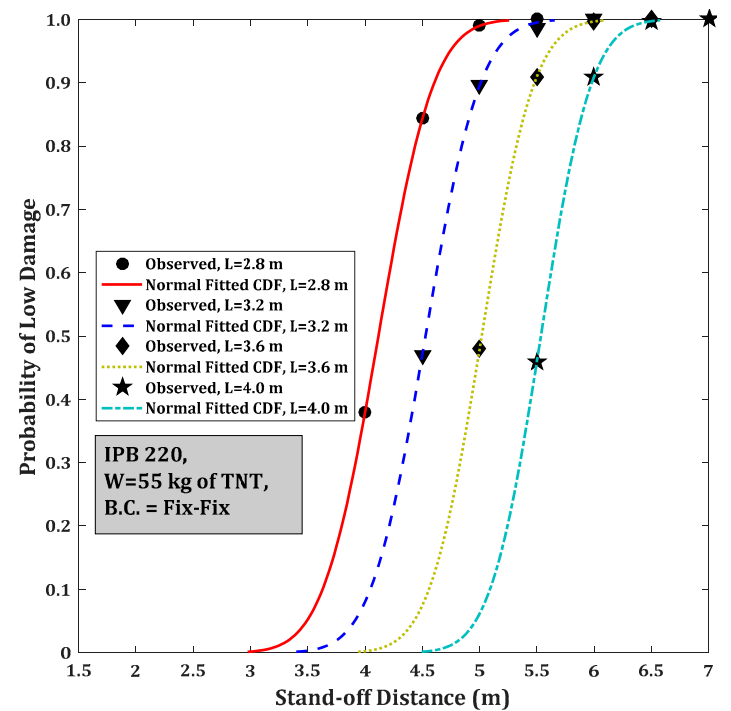

(a)

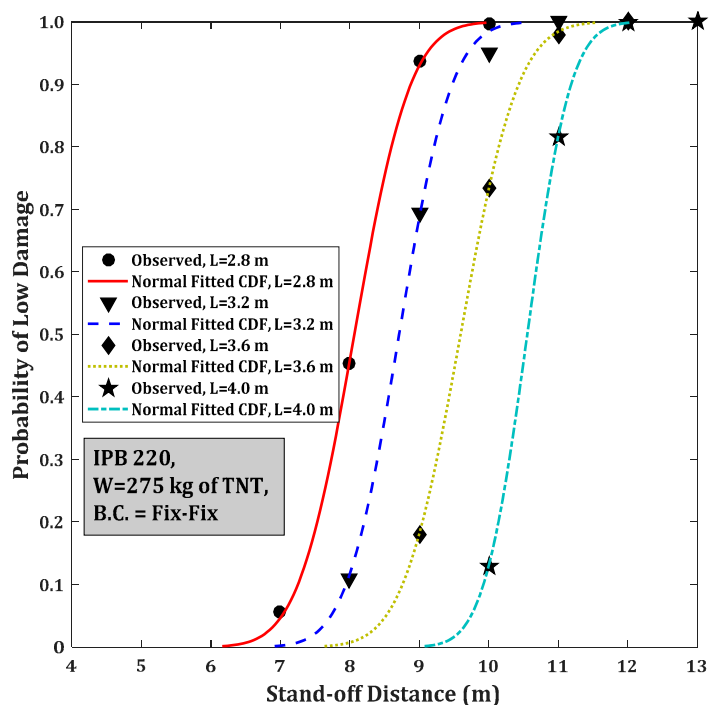

(b)

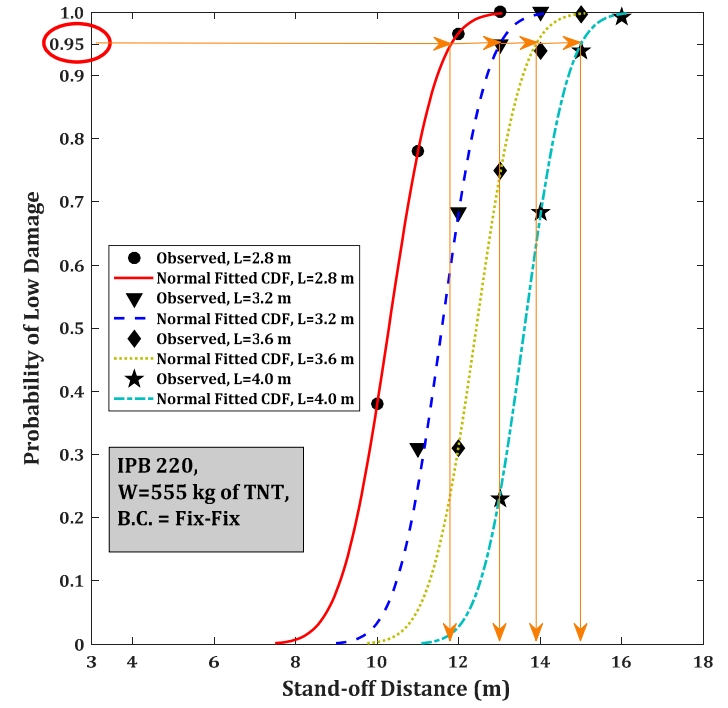

(c)

Figure 7. Curves of probability of low damage for IPB220 with fixed ends and different s lengths, subjected to: (a) 55, (b) 275 and (c) $555 \mathrm{~kg}$ of TNT. 
As shown, when increasing the column length, the SSD also increases. The reason is that the longer the column length (and thus slenderness), the more it is exposed to premature buckling which reduces the overall residual axial load capacity and further results in more severe damage and thus higher SPD value. In the case of fixed ends, according to Figure 7c, the SPD values are obtained in 11.8, 13.0, 13.9 and $15.0 \mathrm{~m}$, which correspond to SSD values of 1.44, 1.58, 1.69 and $1.83 \mathrm{~m} / \mathrm{kg}^{1 / 3}$ for $555 \mathrm{~kg}$ of TNT and column lengths of 2.8, 3.2, 3.6 and $4.0 \mathrm{~m}$, respectively. As evidenced, by changing the support condition from pinned to fixed ends, the calculated SSD decreases. The actual boundary condition has thus a significant effect on the final performances and results. Moreover, considering the fact that the end conditions for real columns are neither fully pinned nor fixed, it is preferable for designers to take into account an actual value between the two limit conditions of perfectly pinned or fixed column models, which ultimately leads to choosing an SPD in between [89].

It should be noted that the variability of stand-off distance is highly dependent on the position of the explosive, given that the location of a terrorist device is not a certain parameter. When the target is known, the minimum stand-off distance from a facility (building, bridge, etc.) is obtained from the knowledge of the site (roads, parking, etc.), the access control (security gates, bollards, etc.) and the perimeter security [78]. Generally, for a critical building that may represent a target for terrorist attacks with variable and portable explosive weights (i.e., by human and different vehicles), the minimum stand-off distance can be easily found using the proposed strategy. Such a minimum stand-off distance can be thus used to provide appropriate access control and security guards around the building, thus ensuring that the risk of damage for the structural members in the first stage and the progressive collapse can be reduced.

Further, the residual axial load carrying capacity of a column (which is used to obtain DI) alternates between minimum (zero) and maximum $\left(\mathrm{P}_{\text {initial }}\right)$ values. This variation depends on geometrical properties and boundaries of the column, as well as on some uncertainties associated with blast loading and material properties. For all the cases in which the SPD is calculated, due to the fact that $95 \%$ probability of low damage is considered as decision criterion, the residual capacity of a given column under a selected blast scenario is expected to approach $P_{\text {initial }}$, or equivalently, the DI values are expected to approach zero. To better clarify the given explanations, Figure 8 shows the DI histograms obtained from MCS for a given IPB260 steel column with length of $3.6 \mathrm{~m}$ and pinned ends, subjected to 55,275 and $555 \mathrm{~kg}$ of TNT. In all these cases, the probabilities of low damage are approximately calculated as 0.95 , and, consequently, the proposed stand-off distances on the top of each figure are related to SPD value for the selected charge weights. As Figure 8 reveals, in all cases, the frequency of the DI obtained from MCS tends to low DI values (almost between DI $=0$ and DI $=0.5$ ), while the possibility of high damage $(0.5<\mathrm{DI}<0.8)$ and collapse (DI $>0.8)$ is really rare.

\subsection{Empirical Relationship for Calculating SSD}

The curves of probability of low damage were extracted similar to the approach presented in Section 5.1 to find the SSD values for all selected configurations (Table 2). Both pinned and fixed end conditions are examined, including different column lengths and explosive charge weights $(55,275$ and $555 \mathrm{~kg}$ of TNT). A large number of FE simulations (approximately 252,000) were conducted for reliability analyses based on MCS, which took nearly $756 \mathrm{~h}$ of run time. The collected data were further investigated to find a practical relationship which could support designers in the predicting the SSD for steel columns under blast loads. By examining the results after a lot of trial-and-error process, it was finally found that the SSD can be expressed as:

$$
\operatorname{SSD}\left(\mathrm{W}, \mathrm{P}_{\text {initial }}\right)=\alpha_{0}+\alpha_{1} \mathrm{~W}+\alpha_{2} \mathrm{P}_{\text {initial }}+\alpha_{3} \mathrm{~W}^{2}+\alpha_{4} \mathrm{~W} \cdot \mathrm{P}_{\text {initial }}+\alpha_{5} \mathrm{P}_{\text {initial }}{ }^{2}
$$

where the parameters $\alpha_{0}$ to $\alpha_{5}$ are constant coefficients. The final values of these $\alpha_{i}$ coefficients, as well as the coefficient of determination $\left(R^{2}\right)$ values, goodness of fit $(\mathrm{GoF})$ 
and root-mean-square error (RMSE), are shown in Table 3 for different columns, as obtained from curve fitting. It is clear that the $\mathrm{R}^{2}$ values are higher than $97 \%$ for all the selected configurations, hence indicating a very satisfactory accuracy of the proposed formula for SSD predictions (usually, $\mathrm{R}^{2}$ values higher than $80 \%$ are considered satisfactory).

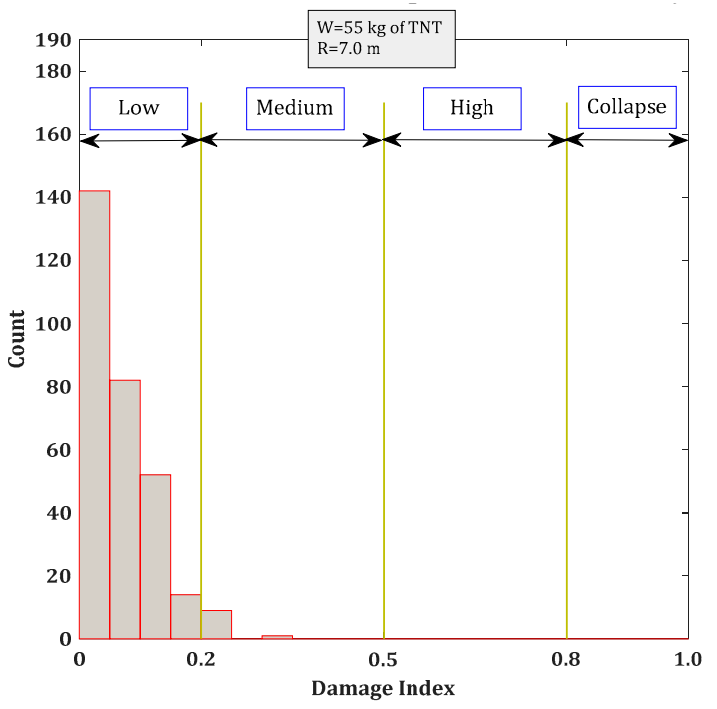

(a)

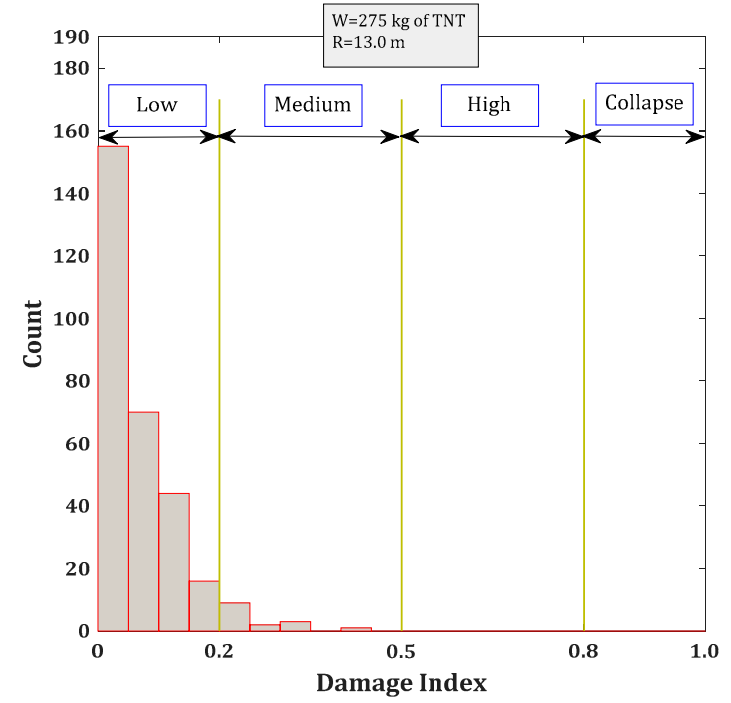

(b)

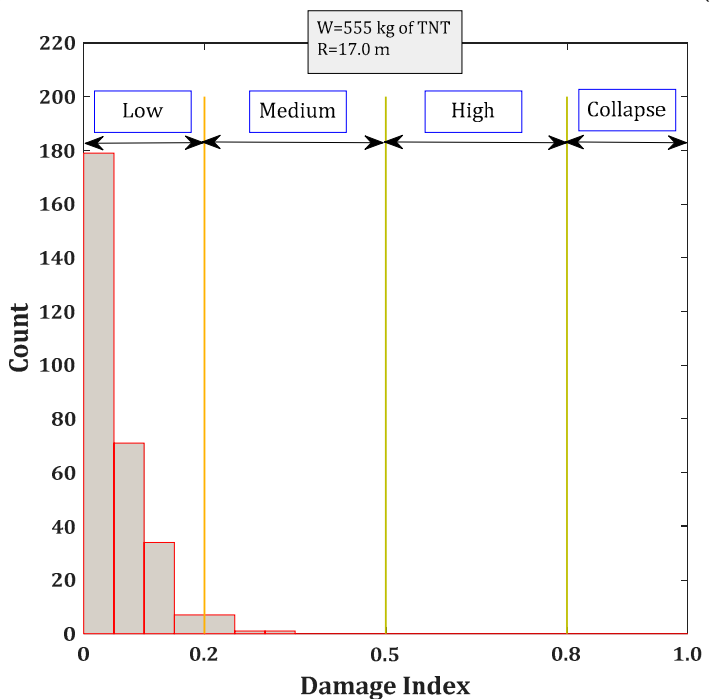

(c)

Figure 8. DI histograms, as obtained from MCS for IPB260 steel column with length of $3.6 \mathrm{~m}$ and pinned ends under: (a) 55, (b) 275 and (c) $555 \mathrm{~kg}$ of TNT.

Table 3. Constant coefficients of Equation (11) and corresponding $\mathrm{R}^{2}$, GoF and RMSE for each selected case (BC = boundary condition).

\begin{tabular}{|c|c|c|c|c|c|c|c|c|c|c|}
\hline BC & Length (m) & $\alpha_{0}$ & $\alpha_{1}$ & $\alpha_{2}$ & $\alpha_{3}$ & $\alpha_{4}$ & $\alpha_{5}$ & $\mathbf{R}^{2}$ & GoF & RMSE \\
\hline \multirow{4}{*}{ Pinned } & 2.80 & +2.600 & $+1.131 \times 10^{-3}$ & $-4.101 \times 10^{-4}$ & $-1.351 \times 10^{-6}$ & $+3.199 \times 10^{-8}$ & $+1.502 \times 10^{-8}$ & 0.9943 & 0.0199 & 0.0364 \\
\hline & 3.20 & +2.765 & $+1.383 \times 10^{-3}$ & $-4.219 \times 10^{-4}$ & $-1.528 \times 10^{-6}$ & $+5.498 \times 10^{-9}$ & $+1.356 \times 10^{-8}$ & 0.9958 & 0.0177 & 0.0343 \\
\hline & 3.60 & +2.959 & $+1.269 \times 10^{-3}$ & $-4.348 \times 10^{-4}$ & $-1.527 \times 10^{-6}$ & $+4.701 \times 10^{-8}$ & $+9.666 \times 10^{-9}$ & 0.9930 & 0.0338 & 0.0475 \\
\hline & 4.00 & +3.056 & $+1.173 \times 10^{-3}$ & $-4.018 \times 10^{-4}$ & $-1.399 \times 10^{-6}$ & $+6.757 \times 10^{-8}$ & $-2.381 \times 10^{-10}$ & 0.9945 & 0.0287 & 0.0437 \\
\hline \multirow{4}{*}{ Fixed } & 2.80 & +1.852 & $+6.884 \times 10^{-4}$ & $-2.723 \times 10^{-4}$ & $-5.899 \times 10^{-7}$ & $+4.833 \times 10^{-9}$ & $+9.599 \times 10^{-9}$ & 0.9825 & 0.0298 & 0.0446 \\
\hline & 3.20 & +2.039 & $+5.398 \times 10^{-4}$ & $-2.825 \times 10^{-4}$ & $-3.748 \times 10^{-7}$ & $-1.978 \times 10^{-9}$ & $+9.041 \times 10^{-9}$ & 0.9739 & 0.0513 & 0.0585 \\
\hline & 3.60 & +2.105 & $+1.046 \times 10^{-3}$ & $-2.847 \times 10^{-4}$ & $-9.854 \times 10^{-7}$ & $-1.322 \times 10^{-8}$ & $+7.141 \times 10^{-9}$ & 0.9771 & 0.0538 & 0.0599 \\
\hline & 4.00 & +2.266 & $+6.718 \times 10^{-4}$ & $-2.705 \times 10^{-4}$ & $-5.376 \times 10^{-7}$ & $+1.577 \times 10^{-8}$ & $+1.872 \times 10^{-9}$ & 0.9782 & 0.0562 & 0.0612 \\
\hline
\end{tabular}


There are two conventional ways to calculate $\mathrm{P}_{\text {initial }}$ : one based on FE modelling and another based on the empirical relationships that are presented in several regulations. In this study, the second method is used, which is easier to apply, is efficient and can be extended to each column, without the need of any complex calculation. The final result is that, even disregarding sophisticated FE methods, the $P_{\text {initial }}$ prediction can be used in Equation (11) and it can be consequently assessed (for a specific explosive charge weight) whether the column is in a safe condition or not. According to the regulations, in more detail, $P_{\text {initial }}$ for members under compression without slender elements can be calculated as:

$$
\begin{aligned}
& \mathrm{P}_{\text {initial }}=\mathrm{F}_{\mathrm{cr}} \times \mathrm{A}_{\mathrm{g}} \\
& \left(\frac{\mathrm{k}_{\mathrm{e}} \mathrm{L}}{\mathrm{r}_{\mathrm{g}}}\right)_{\max } \leq 4.71 \sqrt{\frac{\mathrm{E}_{\mathrm{s}}}{\mathrm{F}_{\mathrm{y}}}} \quad \rightarrow \quad \mathrm{F}_{\mathrm{cr}}=\left[0.658^{\frac{\mathrm{F}_{\mathrm{y}}}{\mathrm{F}_{\mathrm{e}}}}\right] \mathrm{F}_{\mathrm{y}} \\
& \left(\frac{\mathrm{k}_{\mathrm{e}} \mathrm{L}}{\mathrm{r}_{\mathrm{g}}}\right)_{\max }>4.71 \sqrt{\frac{\mathrm{E}_{\mathrm{s}}}{\mathrm{F}_{\mathrm{y}}}} \quad \rightarrow \quad \mathrm{F}_{\mathrm{cr}}=0.877 \mathrm{~F}_{\mathrm{e}}
\end{aligned}
$$

where $\mathrm{F}_{\mathrm{cr}}$ is the critical stress due to flexural buckling and $\mathrm{L}, \mathrm{r}_{\mathrm{g}}$ and $\mathrm{k}_{\mathrm{e}}$ are, respectively, the column length, the radius of gyration and the effective length factor. For a column with pinned ends or fixed ends, it is assumed $\mathrm{k}_{\mathrm{e}}=1$ or $\mathrm{k}_{\mathrm{e}}=0.5$, respectively. Finally, $\mathrm{F}_{\mathrm{e}}$ is the elastic buckling stress which can be calculated as:

$$
F_{e}=\frac{\pi^{2} E_{s}}{\left(\frac{k_{e} L}{r_{g}}\right)^{2}}
$$

Figures 9 and 10 show the predicted SSD values and the corresponding fitted planes (according to Equation (11)) for pinned and fixed ends and for different column lengths. In these figures, the numerical data collected from reliability analyses for different steel configurations and blast scenarios are represented by 21 points which are used for curve fitting (Equation (11)).

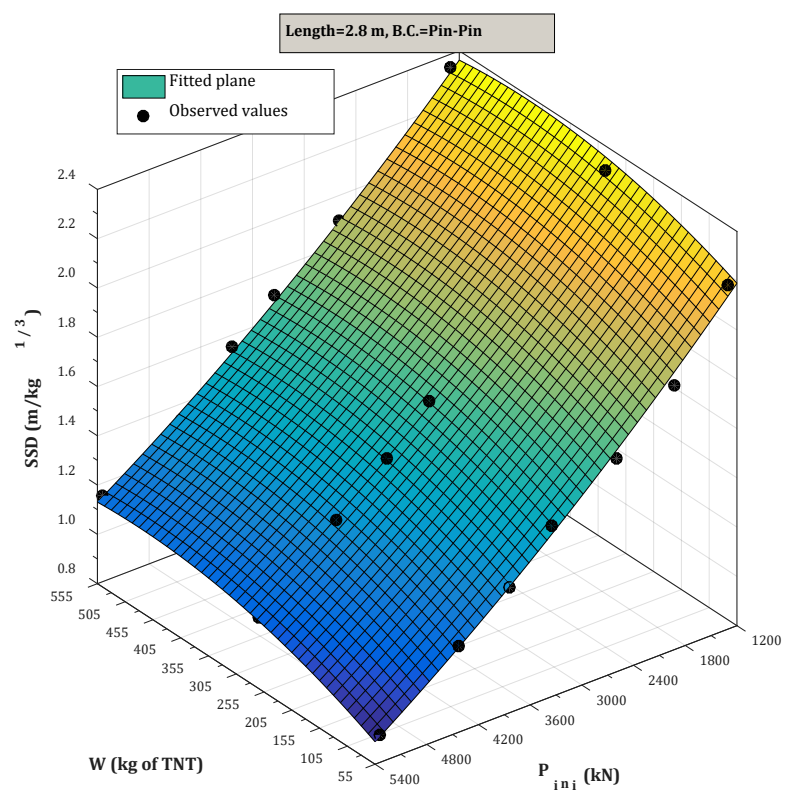

(a)

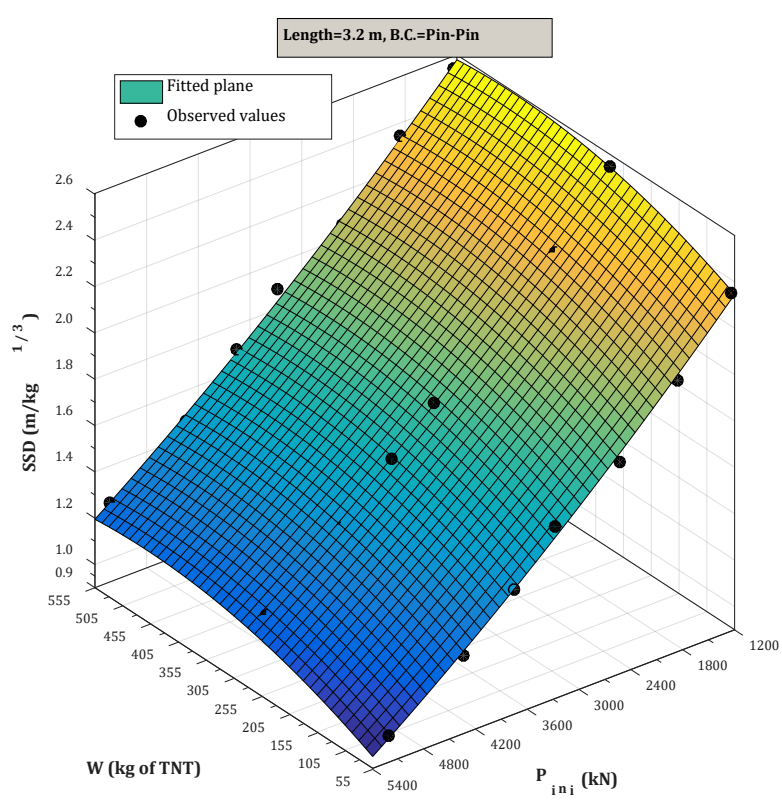

(b)

Figure 9. Cont. 


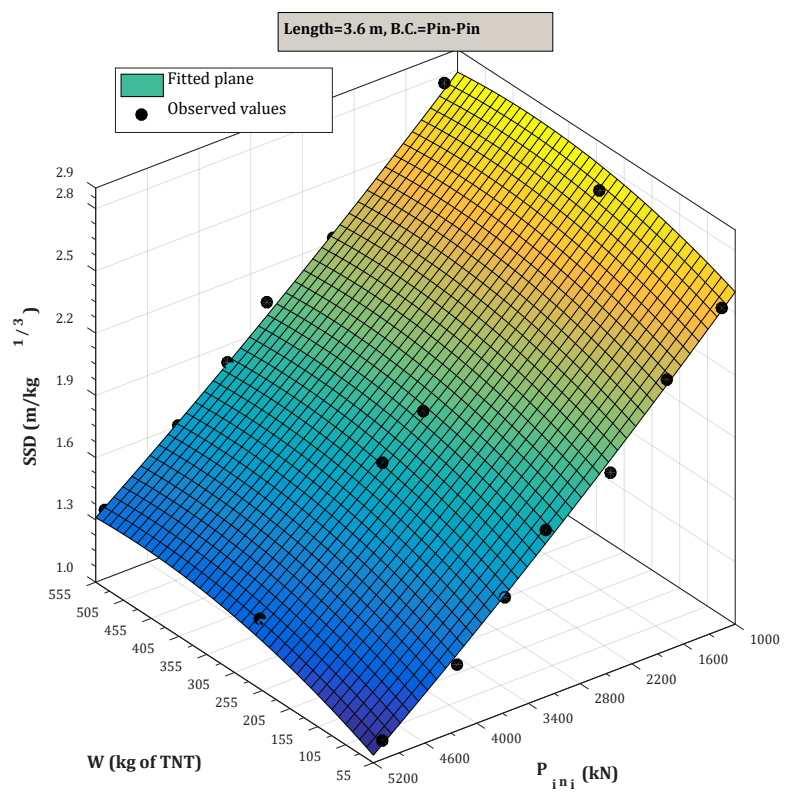

(c)

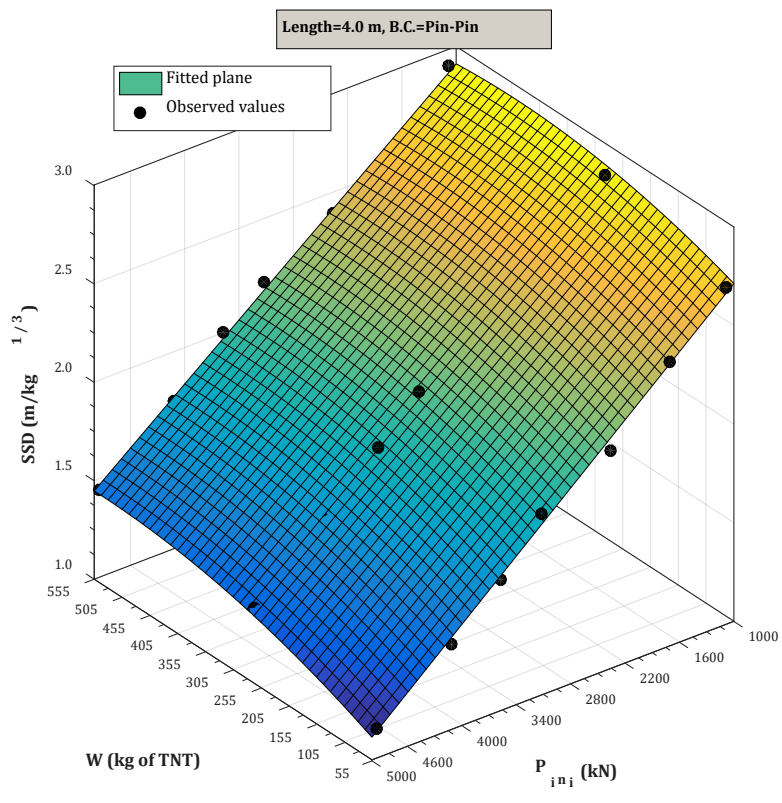

(d)

Figure 9. SSD values for steel columns with pinned ends and different lengths: (a) $\mathrm{L}=2.8 \mathrm{~m},(\mathbf{b}) \mathrm{L}=3.2 \mathrm{~m},(\mathbf{c}) \mathrm{L}=3.6 \mathrm{~m}$ and (d) $\mathrm{L}=4.0 \mathrm{~m}$.

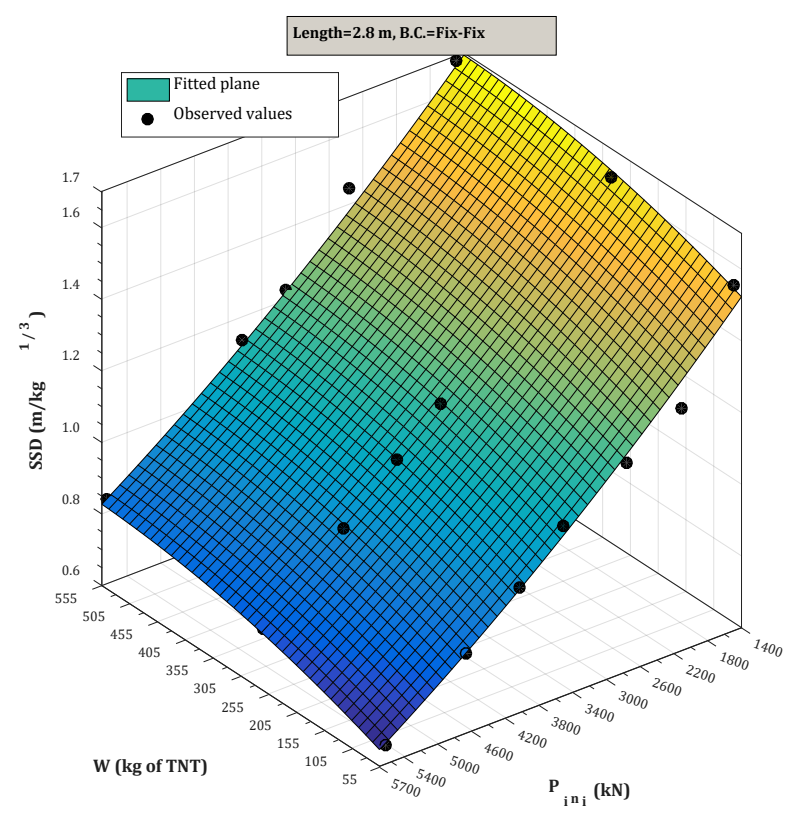

(a)

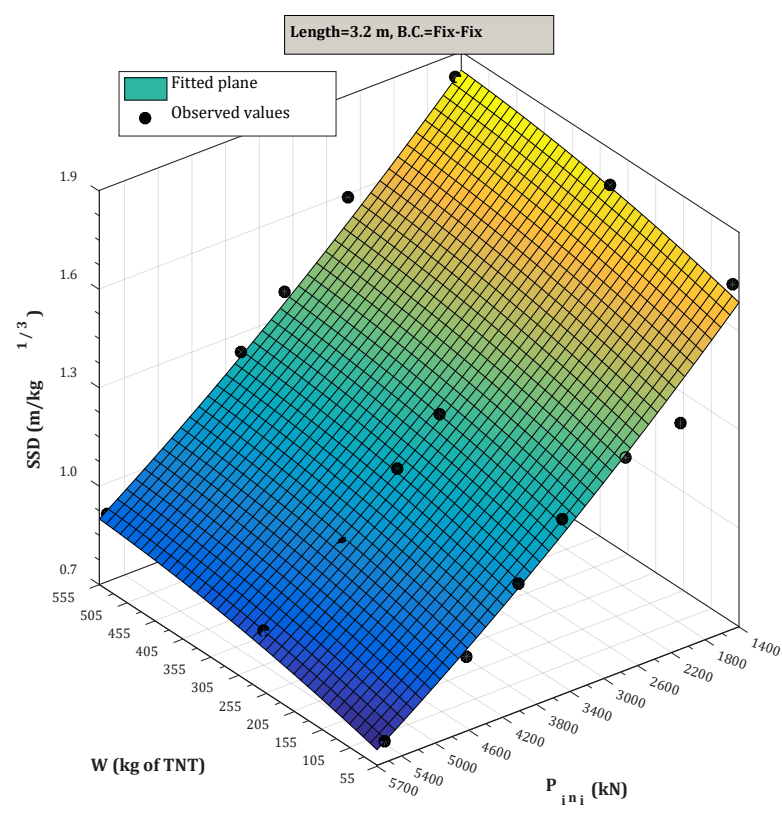

(b)

Figure 10. Cont. 


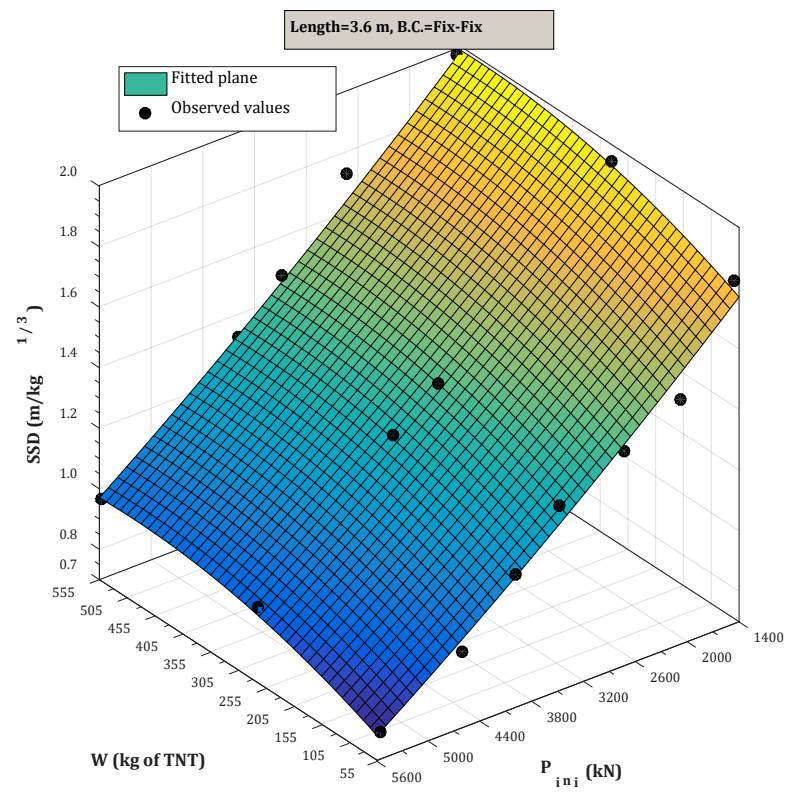

(c)

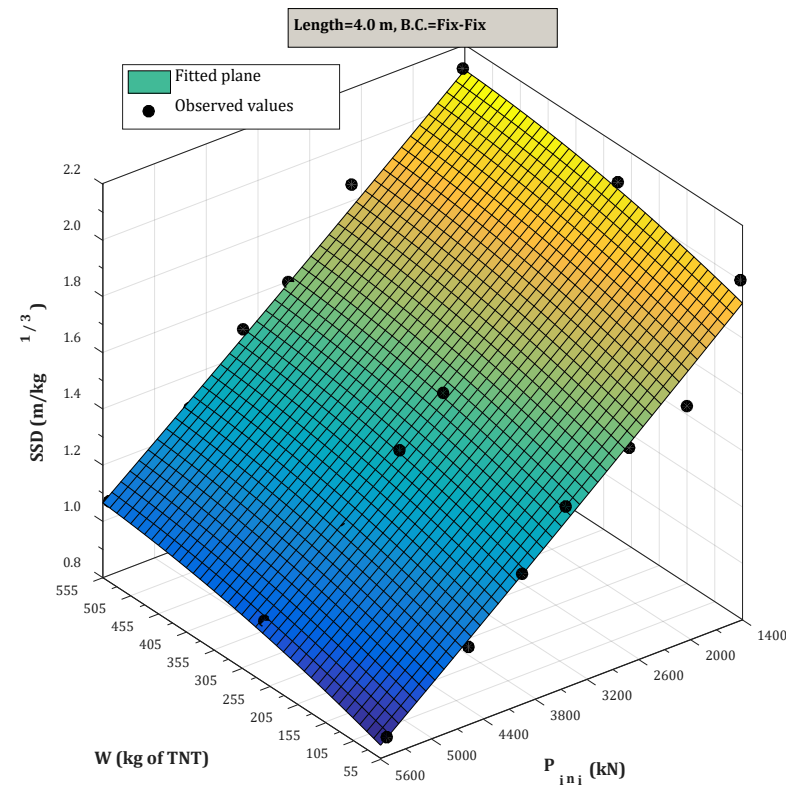

(d)

Figure 10. SSD values for steel columns with fixed ends and different lengths: (a) $\mathrm{L}=2.8 \mathrm{~m},(\mathbf{b}) \mathrm{L}=3.2 \mathrm{~m},(\mathbf{c}) \mathrm{L}=3.6 \mathrm{~m}$ and (d) $\mathrm{L}=4.0 \mathrm{~m}$.

As shown, the SSD value typically increases with increasing explosive charge weight and decreases with increasing initial axial load capacity. For a given column length, by changing the support condition from pinned to fixed, the SSD decreases. Additionally, the effect of the explosive charge weight on SSD is minimum, compared to $P_{\text {initial }}$. For $\mathrm{W}$-values higher than or equal to $275 \mathrm{~kg}$, the effect of $\mathrm{W}$ is almost negligible and the values obtained for SSD are almost identical. In other words, by maintaining $P_{\text {initial }}$ constant, the obtained SSD values for $W=275 \mathrm{~kg}$ of TNT can be still considered for $\mathrm{W}>275 \mathrm{~kg}$, with an acceptable level of accuracy (Equation (14)). For a given $P_{\text {initial }}$ value and a variable $W$, the SPD can be in fact calculated as follows:

$$
\mathrm{SSD}_{(\mathrm{W}=275)} \cong \mathrm{SSD}_{(\mathrm{W}>275)}
$$

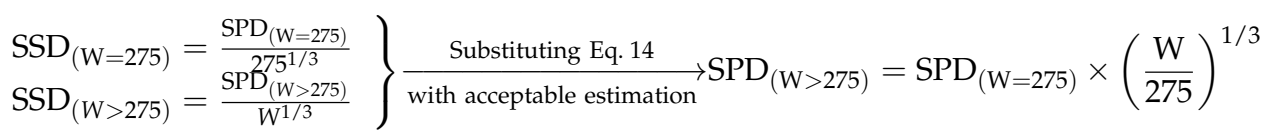

where $\mathrm{SSD}_{(\mathrm{W}=275)}$ and $\mathrm{SSD}_{(\mathrm{W}>275)}$ are the safe scaled distances for $\mathrm{W}=275$ and $\mathrm{W}>275 \mathrm{~kg}$ of TNT, respectively. Similarly, $\mathrm{SPD}_{(\mathrm{W}=275)}$ and $\mathrm{SPD}_{(\mathrm{W}>275)}$ are the $\mathrm{SPD}$ for $\mathrm{W}=275 \mathrm{~kg}$ and $W>275 \mathrm{~kg}$ of TNT, respectively. Based on such an equation, the SPD for W values higher than $275 \mathrm{~kg}$ of TNT can be thus easily obtained, without the need for any further simulation. As an instance, the predicted SSD value for a steel column with IPB 220 section and length of $3.6 \mathrm{~m}$ is 2.22 and 2.15, as obtained for TNT explosive charge weights equal to 555 or $275 \mathrm{~kg}$. This results in SPD values of 18.24 and $13.98 \mathrm{~m}$, respectively. Using Equations (14) and (15), the $\mathrm{SPD}_{(\mathrm{W}>275)}$ for the aforementioned column is calculated as $17.66 \mathrm{~m}$, thus with a minimum percentage scatter $(3.15 \%)$ compared to the expected value.

\subsection{Verification of the Proposed Formula}

The proposed analytical correlation for calculating the SSD was finally further discussed and verified. To this end, the numerical results from [52] were taken into account. 
For a pinned steel column with IPBv200 cross section (ST37 steel) and a total length of $3.6 \mathrm{~m}$, subjected to different charge weights (55, 275 and $555 \mathrm{~kg}$ of TNT), the SPD values in [52] were predicted to be 8,15 and $19 \mathrm{~m}$, thus resulting in SSD values of 2.10, 2.30 and $2.31 \mathrm{~m} / \mathrm{kg}^{1 / 3}$, respectively. The input steel yield stress, density, elastic modulus and Poisson's ratio were set to $240 \mathrm{MPa}, 7850 \mathrm{~kg} / \mathrm{m}^{3}, 210 \mathrm{GPa}$ and 0.3 , respectively. Furthermore, the geometrical characteristics of the resisting section (i.e., b, h, s and t, see Table 2), were set to 206, 220, 15 and $25 \mathrm{~mm}$, respectively. It should be noted that the IPBv200 cross section is different from the intended steel sections presented in Table 2.

In order to analytically predict the SSD value based on Equation (11), the initial axial capacity of the column must first be calculated. Based on Equations (12) and (13), such a value can be estimated as $2518 \mathrm{kN}$. Consequently, by using Equation (14) and the constant coefficients presented in Table 2 (pinned ends and column length of $3.6 \mathrm{~m}$ ), the corresponding SSD are easily calculated for selected explosive charges. The related values of SSD and SPD from Equations (14) and (15), together with those obtained from the previous study [52], are thus compared in Table 4 . As shown, the percentage scatter $\Delta$ is also calculated for each case, giving evidence of the accuracy of the proposed method.

Table 4. Verification results of the proposed formula, with respect to previous study [52].

\begin{tabular}{ccccccc}
\hline \multirow{2}{*}{ W (kg of TNT) } & \multicolumn{3}{c}{ SSD Value $\left(\mathbf{m} / \mathbf{k g}^{\mathbf{1 / 3}}\right)$} & \multicolumn{3}{c}{ SPD (m) } \\
\cline { 2 - 7 } & Hadianfard et al. [52] & Present Study & $\boldsymbol{\Delta} \mathbf{~ ( \% )}$ & Hadianfard et al. [52] & Present Study & $\boldsymbol{\Delta}(\%)$ \\
\hline 55 & 2.10 & 1.99 & 5.24 & 8 & 7.57 & 5.37 \\
275 & 2.30 & 2.18 & 5.21 & 15 & 14.17 & 5.53 \\
555 & 2.31 & 2.21 & 4.33 & 19 & 18.16 & 4.42 \\
\hline
\end{tabular}

As Table 4 reveals, there is in fact a rather close correlation between the current proposed formula for the SSD calculation and the past numerical study reported in [52]. SSD values obtained by Equation (11) were equal to $1.99,2.18$ and $2.21 \mathrm{~m} / \mathrm{kg}^{1 / 3}$, respectively, for explosive charge weights of 55,275 and $555 \mathrm{~kg}$, and thus corresponding to a negligible scatter $(5.24 \%, 5.21 \%$ and $4.33 \%)$ compared to the SSD values from [52].

\section{Calculation Examples}

In conclusion, to emphasize the applicability and usefulness of the proposed relationship, some calculation examples are presented. The objective of these examples is to find the SPD and SSD of:

(i) A steel column with IPB 240 cross section and L $=3.4 \mathrm{~m}$ (Section 1), and

(ii) A box shape steel column with $\mathrm{L}=3.6 \mathrm{~m}$ and given geometrical properties in Table 5 (Section 2).

Table 5. Sectional properties of selected box section steel column for calculation examples.

\begin{tabular}{|c|c|c|c|c|c|c|c|c|c|}
\hline \multicolumn{8}{|c|}{ Section Properties } & \multirow{2}{*}{$\underset{w}{f}$} & \multirow[b]{2}{*}{$\boldsymbol{h}$} \\
\hline Identification & $\mathrm{b}(\mathrm{mm})$ & $\mathrm{h}(\mathrm{mm})$ & $\mathrm{f}(\mathrm{mm})$ & $\mathrm{w}(\mathrm{mm})$ & $\mathrm{A}\left(\mathrm{cm}^{2}\right)$ & $\mathrm{I}_{\mathrm{x}}\left(\mathrm{cm}^{4}\right)$ & $\mathrm{I}_{\mathrm{y}}\left(\mathrm{cm}^{4}\right)$ & & \\
\hline $\mathrm{BOX}$ & 300 & 300 & 19.6 & 6.2 & 149.9 & 24,986 & 15,799 & $\begin{array}{r}b \\
\text { Reference c }\end{array}$ & s section \\
\hline
\end{tabular}

Section 1 differs from the intended columns presented in Table 2. Its length of $3.4 \mathrm{~m}$, in particular, is further modified and differs with considered lengths (i.e., 2.8, 3.2, 3.6 and $4.0 \mathrm{~m}$ ) in the reliability analyses, in order to create a databank for the relationship proposal. Section 2 is selected from [57], in which its sectional properties about bending axis is the same as for a IPB300 steel column, while its cross-sectional shape is totally different. Again, the material yield stress, density, elastic modulus and Poisson's ratio are set equal to $240 \mathrm{MPa}, 7850 \mathrm{~kg} / \mathrm{m}^{3}, 210 \mathrm{GPa}$ and 0.3 , respectively. Finally, Section 1 is subjected to six different explosive charge weights $(55,200,275,350,555$ and $1000 \mathrm{~kg}$ 
of TNT), while Section 2 is subjected to $275 \mathrm{~kg}$ of TNT, under the assumption of two idealized boundary conditions, (a) pinned and (b) fixed ends. The reason for selecting an explosive weight of $1000 \mathrm{~kg}$ of TNT, in this regard, is to verify the accuracy of the proposed Equations (14) and (15) for calculating the SPD and SSD for explosive charge weights higher than $555 \mathrm{~kg}$ of TNT.

To determine the SSD of the selected configurations, the proposed relationship (Equation (11)) and the methodology earlier presented are employed. The results are collected in Table 6, for both the pinned and fixed ends. It is worth mentioning that the SSD values calculated by Equation (11) are obtained by an interpolation approach. This means that, for a column with a length other than those reported in Figures 9 and 10, for both pinned and fixed end conditions, the interpolation method should be always used to calculate the corresponding SSD. For the present calculation example, the SSD values for column lengths of 3.2 and $3.6 \mathrm{~m}$ are thus first calculated by Equation (11) and then, using the interpolation, the required SSD values are estimated for the assigned column length of $3.4 \mathrm{~m}$.

Table 6. SSD and SPD calculations with different methods MCS and proposed practical equations.

\begin{tabular}{|c|c|c|c|c|c|c|c|c|c|c|c|c|}
\hline \multirow[b]{2}{*}{ Column } & \multirow[b]{2}{*}{ B.C } & \multirow[b]{2}{*}{$\begin{array}{c}\text { W } \\
(\mathrm{kg} \text { of } \mathrm{TNT})\end{array}$} & \multicolumn{5}{|c|}{$\operatorname{SSD}\left(\mathrm{kg} / \mathrm{m}^{1 / 3}\right)$} & \multicolumn{5}{|c|}{ SPD (m) } \\
\hline & & & 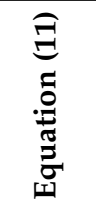 & 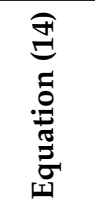 & MCS & $\Delta_{1}(\%)$ & $\Delta_{2}(\%)$ & 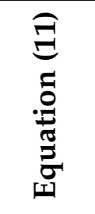 & 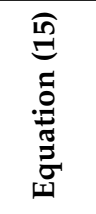 & MCS & $\Delta_{1}(\%)$ & $\Delta_{3}(\%)$ \\
\hline \multirow{12}{*}{$\begin{array}{l}\text { IPB } \\
240\end{array}$} & \multirow{6}{*}{ Pinned } & 55 & 2.052 & - & 2.039 & 0.63 & - & 7.80 & - & 7.75 & 0.64 & - \\
\hline & & 200 & 2.192 & - & 2.077 & 5.24 & - & 12.82 & - & 12.15 & 5.23 & - \\
\hline & & 275 & 2.244 & 2.244 & 2.214 & 1.34 & 1.33 & 14.59 & 14.59 & 14.40 & 1.30 & 1.30 \\
\hline & & 350 & 2.254 & 2.244 & 2.172 & 3.63 & 3.20 & 15.88 & 15.81 & 15.31 & 3.58 & 3.16 \\
\hline & & 555 & 2.274 & 2.244 & 2.265 & 0.39 & 0.93 & 18.69 & 18.44 & 18.61 & 0.43 & 0.91 \\
\hline & & 1000 & - & 2.244 & 2.278 & - & 1.49 & - & 22.44 & 22.78 & - & 1.49 \\
\hline & \multirow{6}{*}{ Fixed } & 55 & 1.466 & - & 1.416 & 3.41 & - & 5.58 & - & 5.38 & 3.58 & - \\
\hline & & 200 & 1.532 & - & 1.438 & 6.14 & - & 8.96 & - & 8.41 & 6.13 & - \\
\hline & & 275 & 1.587 & 1.587 & 1.533 & 3.40 & 3.40 & 10.32 & 10.32 & 9.97 & 3.39 & 3.39 \\
\hline & & 350 & 1.614 & 1.587 & 1.558 & 3.46 & 1.83 & 11.37 & 11.18 & 10.98 & 3.43 & 1.78 \\
\hline & & 555 & 1.646 & 1.587 & 1.657 & 0.66 & 4.22 & 13.53 & 13.04 & 13.62 & 0.66 & 4.26 \\
\hline & & 1000 & - & 1.587 & 1.598 & - & 2.92 & - & 15.87 & 15.98 & - & 0.69 \\
\hline \multirow{2}{*}{ BOX } & Pinned & 275 & 1.874 & 1.874 & 1.811 & 3.36 & 3.36 & 12.18 & 12.18 & 11.78 & 3.28 & 3.28 \\
\hline & Fixed & 275 & 1.386 & 1.386 & 1.396 & 0.71 & 0.71 & 9.01 & 9.01 & 9.08 & 0.77 & 0.77 \\
\hline
\end{tabular}

From Table 6, see Section 1, it is possible to notice that the proposed equation is able to provide a good level of accuracy for the estimation of the expected SSD under different explosive charge weights. Such an outcome is confirmed by the calculated percentage scatters, obtained between Equation (11) and MCS as $\Delta_{1}$, and between Equation (14) and a MCS as $\Delta_{2}$, and between Equation (15) and MCS as $\Delta_{3}$. It should be noted that the symbol dash (-) in Table 6 shows that input value of $\mathrm{W}$ is out of range for corresponding equation. Furthermore, for Section 2, it can be seen that the proposed relationship accurately predicts the required SPD and SSD values, in comparison to the FE-based MCS results. This is also consistent with the results presented in [57], where for steel columns with different crosssectional shapes (but similar section properties) subjected to the same loading/boundary conditions, it was proved that the cross section shape has mostly null effects on the global response. In case of pinned ends, in more detail, the cross-sectional shape has little effect on the response of a given column, while in case of fixed ends the results may change up to $20 \%$ [57].

In this paper, the results obtained for Section 2 show that, for a non $\mathrm{H}$-shape steel column that can be equaled to an $\mathrm{H}$-section (within the examined range and with the 
same loading/boundary conditions), the proposed formula can be used with accuracy to determine the SPD and SSD parameters. It should be kept in mind, however, that the proposed relationship is generally based on interpolation within the range of the intended columns. In general, it is hence recognized that the use of the proposed formula for other steel columns can provide a preliminary estimation of the required SPD and SSD values, but the accuracy of these results should be examined through engineering judgment and further investigations.

It is also clear, in this regard, that considering the high computational cost of the rigorous approach (almost $0.9 \mathrm{~h}$ for 300 simulations, and almost $4.5 \mathrm{~h}$ for each curve of probability of low damage, consisting of 5 points), the proposed approximate relationships can be efficiently used to obtain practical and reliable estimates.

The illustrative calculation examples, in conclusion, proved that the proposed formula is capable of properly interpolating the available data, and thus finding the SSD of various types of columns, which may differ in length and/or cross-sectional properties. Furthermore, such a relationship could be further extended to find the SSD of blast loaded steel columns with semi-fixed boundary conditions. Recently, a research study was in fact reported in [89] to investigate the effect of semi-fixed supports on the response of flexural members under impact loads. The equivalent SDOF system was used and the transformation factors including load, mass, stiffness and ultimate resistance factors were obtained for different fixity values in the elastic, elastic-plastic and plastic regions. It was thus shown that the semi-fixed condition can severely affect the blast response of a given column, compared to the two ideal assumptions of fully pinned and fully fixed support conditions. Accordingly, it is recognized that the current research outcomes-based on the SSD results for two perfectly pinned and fixed conditions-can support the designer with their engineering judgment in the choice of the SSD value (in between two limit support conditions) which is closest to the real boundary condition.

\section{Conclusions}

Safe scaled distance (SSD) is of practical interest, especially for design purposes of structural elements or assemblies, in order to minimize the damage probability and consequently the risk of progressive collapse against terrorist attacks in congested urban areas. In this paper, an improved methodology based on reliability analysis and implementing the beam element formulation was presented for calculating the SSD and the safe protective distance (SPD) for steel beam columns subjected to blast loads. To obtain the probability of low damage, the Monte Carlo simulation (MCS) method was used, so as to account for the uncertainties of blast loading parameters and material properties. The proposed methodology was extended to steel columns with different cross sections (IPB180 to IPB500), lengths $(2.8,3.2,3.6$ and $4.0 \mathrm{~m})$ and boundary conditions (pinned or fixed ends). The collected data were thus further investigated to find a practical relationship to predict the SSD of steel columns under blast loads. From the comparative discussion, the following conclusions were obtained:

- The results showed that the improved methodology, based on the beam element formulation, has good efficiency and accuracy in predicting the damage probability of blast loaded steel columns and further remarkably reduces the run time of probabilistic analyses.

- A practical relationship was proposed and verified against numerical studies in the literature, to relate the SSD of blast loaded steel columns to the initial axial capacity and explosive charge weight.

- The proposed equation has a very good agreement with FE results based on MCS, which indicates its very high level of accuracy in predicting the SSD and thus its efficiency in obtaining practical and reliable estimates.

- The results showed that for both pinned and fixed end conditions, by increasing the initial axial carrying capacity of a given column and the amount of explosive charge weight, the SSD decreases and increases, respectively. The variation of the explosive 
charge weight, however, has minimum effects on the calculated SSD, compared to variations in the initial axial capacity of the column.

- The discussed results proved that upon changing the support condition from pinned to fixed ends, the corresponding SSD decreases significantly. This indicates that the actual boundary condition has substantial effects on the SSD and the designer should consequently select an SSD value between two perfectly pinned and fixed models to account for real support conditions.

- For explosive charge weights (W) higher than or equal to $275 \mathrm{~kg}$ of TNT, by keeping constant the initial axial capacity, the effects of $\mathrm{W}$ variations on SSD are almost negligible. In a nutshell, the SSD obtained for $\mathrm{W}=275 \mathrm{~kg}$ of TNT can be rationally taken into account, with an acceptable level of accuracy, for $\mathrm{W}$ values higher than $275 \mathrm{~kg}$ of TNT $\left(\mathrm{SSD}_{(\mathrm{W}=275)} \cong \mathrm{SSD}_{(\mathrm{W}>275)}\right)$.

- Similarly, the SPD of a given steel column subjected to explosive charge weights higher than or equal to $275 \mathrm{~kg}$ of TNT can be easily obtained by calculating the SPD for $\mathrm{W}=275 \mathrm{~kg}$ of TNT using the proposed equation.

Author Contributions: Conceptualization, M.M., C.B., M.A.H. and A.B.; methodology, M.M., C.B., M.A.H. and A.B.; software, M.M., C.B., M.A.H. and A.B.; validation, M.M., C.B., M.A.H. and A.B.; formal analysis, M.M., C.B., M.A.H. and A.B.; investigation, M.M., C.B., M.A.H. and A.B.; writingoriginal draft preparation, M.M., C.B., M.A.H. and A.B.; writing-review and editing, M.M., C.B., M.A.H. and A.B.; visualization, M.M., C.B., M.A.H. and A.B.; supervision, C.B., M.A.H. and A.B. All authors have read and agreed to the published version of the manuscript.

Funding: This research received no external funding.

Institutional Review Board Statement: Not applicable.

Informed Consent Statement: Not applicable.

Data Availability Statement: Supporting data will be made available upon request.

Acknowledgments: The authors wish to acknowledge and express their special thanks to Sina Malekpour and Fateme Hajari from Department of Civil and Environmental Engineering, Shiraz University of Technology, Shiraz, Iran.

Conflicts of Interest: The authors declare no conflict of interest.

$\begin{array}{ll}\text { Abbreviations } & \\ \text { MCS } & \text { Monte Carlo Simulation } \\ \text { SPD } & \text { Safe Protective Distance } \\ \text { SSD } & \text { Safe Scaled Distance } \\ \text { FE } & \text { Finite Element } \\ \text { RC } & \text { Reinforced Concrete } \\ \text { SDOF } & \text { Single Degree of Freedom } \\ \text { MDOF } & \text { Multi Degree of Freedom } \\ \text { DIF } & \text { Dynamic Increase Factor } \\ \text { DI } & \text { Damage Index } \\ \text { GoF } & \text { Goodness of Fit } \\ \text { RMSE } & \text { Root-Mean-Square Error } \\ \text { R } & \text { Coefficient of determination } \\ \text { PDF } & \text { Probability Density Function } \\ \text { CDF } & \text { Cumulative Distribution Function } \\ \text { COV } & \text { Coefficient of Variation } \\ \text { TNT } & \text { Trinitrotoluene } \\ \text { BC } & \text { Boundary Condition } \\ \text { W } & \text { Explosive charge weight } \\ \text { W } & \text { Eff }\end{array}$




\begin{tabular}{|c|c|}
\hline $\mathrm{Z}$ & Scaled distance \\
\hline $\mathrm{C}$ and $\mathrm{P}$ & Constant coefficients of Cooper-Simonds relationship \\
\hline $\mathrm{k}$ & Integration refinement factor \\
\hline$\sigma$ & Standard deviation \\
\hline$\varepsilon_{\mathrm{t}}$ & True stress \\
\hline$\varepsilon_{\mathrm{t}}$ & True strain \\
\hline$\dot{\varepsilon}$ & Strain rate \\
\hline $\mathrm{L}_{1}$ & Deformed length of uniaxial tension member \\
\hline $\mathrm{L}_{0}$ & Undeformed length of uniaxial tension member \\
\hline $\mathrm{P}_{\mathrm{r}}$ & Reflected pressure \\
\hline $\mathrm{P}_{\mathrm{r}(\mathrm{mean})}$ & Mean value of reflected pressure \\
\hline$\sigma_{\operatorname{Pr}}$ & Standard deviation of reflected pressure \\
\hline $\mathrm{COV}_{\mathrm{pr}}$ & Coefficient of variation of reflected pressure \\
\hline$t_{d}$ & Positive time duration \\
\hline$t_{d(\text { mean })}$ & Mean value of positive time duration \\
\hline$\sigma_{\mathrm{td}}$ & Standard deviation of positive time duration \\
\hline $\mathrm{COV}_{\mathrm{td}}$ & Coefficient of variation of positive time duration \\
\hline$P_{\text {residual }}$ & Post-blast residual axial capacity of the damaged column \\
\hline$P_{\text {initial }}$ & Maximum axial load-carrying capacity of the undamaged column \\
\hline $\mathrm{F}_{\mathrm{y}}$ & Yield stress \\
\hline $\mathrm{E}_{\mathrm{S}}$ & Modulus of elasticity \\
\hline $\mathrm{E}_{\mathrm{t}}$ & Slope of the bilinear stress strain curve in strain hardening region \\
\hline$P_{f}$ & Probability of failure \\
\hline $\mathrm{N}_{\mathrm{f}}$ & Number of trials for which limit state function falls in the failure region \\
\hline $\mathrm{N}$ & Number of total simulations \\
\hline $\mathbf{X}$ & Vector of input random variables \\
\hline$g(\mathbf{X})$ & Limit state function \\
\hline $\mathrm{r}$ & Capacity \\
\hline q & Demand \\
\hline$f_{x}(X)$ & Joint probability density function \\
\hline $\mathrm{I}_{\mathrm{F}}$ & Failure indicator \\
\hline $\mathrm{C}_{\mathrm{L}}$ & Confidence level \\
\hline $\mathrm{I}_{\mathrm{x}}$ & Moment of inertia about the strong axis \\
\hline $\mathrm{I}_{\mathrm{y}}$ & Moment of inertia about the weak axis \\
\hline$\alpha_{0}$ to $\alpha_{5}$ & Constant coefficients \\
\hline $\mathrm{F}_{\mathrm{cr}}$ & Critical stress due to flexural buckling of members without slender elements \\
\hline$A_{g}$ & Total cross-sectional area \\
\hline $\mathrm{L}$ & Column length \\
\hline$r_{g}$ & Radius of gyration \\
\hline $\mathrm{k}_{\mathrm{e}}$ & Effective length factor \\
\hline $\mathrm{F}_{\mathrm{e}}$ & Elastic buckling stress \\
\hline$\Delta, \Delta_{1}, \Delta_{2}$ and $\Delta_{3}$ & Percentage scatters \\
\hline
\end{tabular}

\section{References}

1. Soft Targets and Crowded Places Security Plan Overview; U.S. Department of Homeland Security: Washington, DC, USA, 2018. Available online: https:/ / www.cisa.gov/sites / default/files/publications/DHS-Soft-Target-Crowded-Place-Security-Plan-Overview052018-508_0.pdf (accessed on 25 November 2021).

2. Hinman, E. Primer for design of commercial buildings to mitigate terrorist attacks. FEMA 2003, 427, 40-41.

3. Command, U.A.M. Engineering Design Handbook: Explosions in Air Part One; AD/A-003 817 (AMC Pamphlet AMCP 706-181); AMC Pamphlet: Alexandria, VA, USA, 1974.

4. $\quad$ Baker, W.E.; Westine, P.S.; Dodge, F.T. Similarity Methods in Engineering Dynamics: Theory and Practice of Scale Modeling; Hayden Book Co.: Indianapolis, IN, USA, 1973; Available online: https:/ /www.elsevier.com/books/similarity-methods-in-engineeringdynamics / westine/978-0-444-88156-4 (accessed on 25 November 2021).

5. U.S. DoD. Ammunition and Explosives Safety Standards; U.S. DoD: Washington, DC, USA, 2004.

6. $\mathrm{Wu}, \mathrm{C}$; $\mathrm{Hao}, \mathrm{H}$. Safe scaled distance for masonry infilled RC frame structures subjected to airblast loads. J. Perform. Constr. Facil. 2007, 21, 422-431. [CrossRef]

7. Byfield, M.; Paramasivam, S. Estimating safe scaled distances for columns subjected to blast. Eng. Comput. Mech. 2014, 167, 23-29. [CrossRef] 
8. Thomas, R.; Steel, K.; Sorensen, A.D. Reliability analysis of circular reinforced concrete columns subject to sequential vehicular impact and blast loading. Eng. Struct. 2018, 168, 838-851. [CrossRef]

9. Hadianfard, M.A.; Malekpour, S. Evaluation of explosion safe distance of steel column via structural reliability analysis. ADST J. 2017, 8, 349-359.

10. Zhai, X.; Wang, Y.; Sun, Z. Damage model and damage assessment for single-layer reticulated domes under exterior blast load. Mech. Based Des. Struct. Mach. 2019, 47, 319-338. [CrossRef]

11. Hao, H.; Wu, C. Numerical simulation of damage of low-rise RC frame structures with infilled masonry walls to explosive loads. Aust. J. Struct. Eng. 2006, 7, 13-22. [CrossRef]

12. Bounds, W.L. Design of Blast-Resistant Buildings in Petrochemical Facilities; ASCE Publications: Reston, VA, USA, 2010.

13. Jarrett, D. Derivation of the British explosives safety distances. Ann. N. Y. Acad. Sci. 1968, 152, 18-35. [CrossRef]

14. Magallanes, J.M.; Martinez, R.; Koenig, J.W. Experimental Results of the AISC Full-Scale Column Blast Test; The American Institute of Steel Construction: Chicago, IL, USA, 2006.

15. Nassr, A.A.; Razaqpur, A.G.; Tait, M.J.; Campidelli, M.; Foo, S. Dynamic response of steel columns subjected to blast loading. J. Struct. Eng. 2013, 140, 04014036. [CrossRef]

16. Nassr, A.A.; Razaqpur, A.G.; Tait, M.J.; Campidelli, M.; Foo, S. Strength and stability of steel beam columns under blast load. Int. J. Impact Eng. 2013, 55, 34-48. [CrossRef]

17. Nassr, A.A.; Razaqpur, A.G.; Tait, M.J.; Campidelli, M.; Foo, S. Single and multi degree of freedom analysis of steel beams under blast loading. Nucl. Eng. Des. 2012, 242, 63-77. [CrossRef]

18. Bao, X.; Li, B. Residual strength of blast damaged reinforced concrete columns. Int. J. Impact Eng. 2010, 37, 295-308. [CrossRef]

19. Momeni, M.; Hadianfard, M.A.; Bedon, C.; Baghlani, A. Damage evaluation of H-section steel columns under impulsive blast loads via gene expression programming. Eng. Struct. 2020, 219, 110909. [CrossRef]

20. Rong, H.-C.; Li, B. Probabilistic response evaluation for RC flexural members subjected to blast loadings. Struct. Saf. 2007, 29, 146-163. [CrossRef]

21. Yokoyama, T. Limits to Deflected Shape Assumptions of the SDOF Methodology for Analyzing Structural Components Subject to Blast Loading. J. Perform. Constr. Facil. 2014, 29, B4014008. [CrossRef]

22. Crawford, J.E.; Magallanes, J.M. The effects of modeling choices on the response of structural components to blast effects. Int. J. Prot. Struct. 2011, 2, 231-266. [CrossRef]

23. Al-Thairy, H. A modified single degree of freedom method for the analysis of building steel columns subjected to explosion induced blast load. Int. J. Impact Eng. 2016, 94, 120-133. [CrossRef]

24. Lee, K.; Kim, T.; Kim, J. Local response of W-shaped steel columns under blast loading. Struct. Eng. Mech. 2009, 31, 25-38. [CrossRef]

25. Shi, Y.; Hao, H.; Li, Z.-X. Numerical derivation of pressure-impulse diagrams for prediction of RC column damage to blast loads. Int. J. Impact Eng. 2008, 35, 1213-1227. [CrossRef]

26. Hadianfard, M.A.; Farahani, A. On the effect of steel columns cross sectional properties on the behaviours when subjected to blast loading. Struct. Eng. Mech. 2012, 44, 449-463. [CrossRef]

27. Hadianfard, M.A.; Nemati, A.; Johari, A. Investigation of Steel Column Behavior with Different Cross Section under Blast Loading. Modares Civ. Eng. J. 2016, 16, 265-278.

28. Ibrahim, Y.E.; Nabil, M. Assessment of structural response of an existing structure under blast load using finite element analysis. Alex. Eng. J. 2019, 58, 1327-1338. [CrossRef]

29. Amadio, C.; Bedon, C. Blast analysis of laminated glass curtain walls equipped by viscoelastic dissipative devices. Buildings 2012, 2, 359-383. [CrossRef]

30. Momeni, M.; Bedon, C. Uncertainty Assessment for the Buckling Analysis of Glass Columns with Random Parameters. Int. J. Struct. Glass Adv. Mater. Res. 2020, 4, 254-275. [CrossRef]

31. Figuli, L.; Cekerevac, D.; Bedon, C.; Leitner, B. Numerical analysis of the blast wave propagation due to various explosive charges. Adv. Civ. Eng. 2020, 2020, 8871412. [CrossRef]

32. Goel, M.D.; Thimmesh, T.; Shirbhate, P.; Bedon, C. Enhanced Single-Degree-of-Freedom Analysis of Thin Elastic Plates Subjected to Blast Loading Using an Energy-Based Approach. Adv. Civ. Eng. 2020, 2020, 8825072. [CrossRef]

33. Shi, Y.; Stewart, M.G. Damage and risk assessment for reinforced concrete wall panels subjected to explosive blast loading. Int. J. Impact Eng. 2015, 85, 5-19. [CrossRef]

34. Bogosian, D.; Ferritto, J.; Shi, Y. Measuring Uncertainty and Conservatism in Simplified Blast Models; Karagozian And Case Glendale: Glendale, CA, USA, 2002.

35. Hao, H.; Stewart, M.G.; Li, Z.-X.; Shi, Y. RC column failure probabilities to blast loads. Int. J. Prot. Struct. $2010,1,571-591$. [CrossRef]

36. Low, H.Y.; Hao, H. Reliability analysis of reinforced concrete slabs under explosive loading. Struct. Saf. 2001, 23, 157-178. [CrossRef]

37. Netherton, M.D.; Stewart, M.G. Blast load variability and accuracy of blast load prediction models. Int. J. Prot. Struct. 2010, 1, 543-570. [CrossRef]

38. Kelliher, D.; Sutton-Swaby, K. Stochastic representation of blast load damage in a reinforced concrete building. Struct. Saf. 2012, 34, 407-417. [CrossRef] 
39. Olmati, P.; Sagaseta, J.; Cormie, D.; Jones, A. Simplified reliability analysis of punching in reinforced concrete flat slab buildings under accidental actions. Eng. Struct. 2017, 130, 83-98. [CrossRef]

40. Ding, Y.; Song, X.; Zhu, H.-T. Probabilistic progressive collapse analysis of steel frame structures against blast loads. Eng. Struct. 2017, 147, 679-691. [CrossRef]

41. Low, H.Y.; Hao, H. Reliability analysis of direct shear and flexural failure modes of RC slabs under explosive loading. Eng. Struct. 2002, 24, 189-198. [CrossRef]

42. Hao, H.; Li, Z.-X.; Shi, Y. Reliability analysis of RC columns and frame with FRP strengthening subjected to explosive loads. J. Perform. Constr. Facil. 2015, 30, 04015017. [CrossRef]

43. Shi, Y.; Stewart, M.G. Spatial reliability analysis of explosive blast load damage to reinforced concrete columns. Struct. Saf. 2015, 53, 13-25. [CrossRef]

44. Stewart, M.G. Reliability-based load factors for airblast and structural reliability of reinforced concrete columns for protective structures. Struct. Infrastruct. Eng. 2019, 15, 634-646. [CrossRef]

45. Olmati, P.; Petrini, F.; Gkoumas, K. Fragility analysis for the Performance-Based Design of cladding wall panels subjected to blast load. Eng. Struct. 2014, 78, 112-120. [CrossRef]

46. Stochino, F. RC beams under blast load: Reliability and sensitivity analysis. Eng. Fail. Anal. 2016, 66, 544-565. [CrossRef]

47. Hussein, A.; Mahmoud, H.; Heyliger, P. Probabilistic analysis of a simple composite blast protection wall system. Eng. Struct. 2020, 203, 109836. [CrossRef]

48. Campidelli, M.; El-Dakhakhni, W.; Tait, M.; Mekky, W. Blast design-basis threat uncertainty and its effects on probabilistic risk assessment. ASCE-ASME J. Risk Uncertain. Eng. Syst. Part A Civ. Eng. 2015, 1, 04015012. [CrossRef]

49. Hedayati, M.H.; Sriramula, S.; Neilson, R.D. Reliability of Profiled Blast Wall Structures. In Numerical Methods for Reliability and Safety Assessment; Springer: Berlin/Heidelberg, Germany, 2015; pp. 387-405.

50. Borenstein, E.; Benaroya, H. Sensitivity analysis of blast loading parameters and their trends as uncertainty increases. J. Sound Vib. 2009, 321, 762-785. [CrossRef]

51. Momeni, M.; Hadianfard, M.A.; Baghlani, A. Implementation of Weighted Uniform SimulationMethod in Failure Probability Analysisof Steel Columns under Blast Load. In Proceedings of the 11th International Congress on Civil Engineering, University of Tehran, Tehran, Iran, 8-10 May 2018.

52. Hadianfard, M.A.; Malekpour, S.; Momeni, M. Reliability analysis of H-section steel columns under blast loading. Struct. Saf. 2018, 75, 45-56. [CrossRef]

53. Thöns, S.; Stewart, M.G. On decision optimality of terrorism risk mitigation measures for iconic bridges. Reliab. Eng. Syst. Saf. 2019, 188, 574-583. [CrossRef]

54. Stewart, M.G.; Netherton, M.D. A Probabilistic Risk-Acceptance Model for Assessing Blast and Fragmentation Safety Hazards. Reliab. Eng. Syst. Saf. 2019, 191, 106492. [CrossRef]

55. Stewart, M.G.; Netherton, M.D. Security risks and probabilistic risk assessment of glazing subject to explosive blast loading. Reliab. Eng. Syst. Saf. 2008, 93, 627-638. [CrossRef]

56. Netherton, M.D.; Stewart, M.G. Risk-based blast-load modelling: Techniques, models and benefits. Int. J. Prot. Struct. 2016, 7, 430-451. [CrossRef]

57. Momeni, M.; Hadianfard, M.A.; Bedon, C.; Baghlani, A. Numerical damage evaluation assessment of blast loaded steel columns with similar section properties. Structures 2019, 20, 189-203. [CrossRef]

58. Hallquist, J.O. LS-DYNA Theory Manual. Livermore Softw. Technol. Corp. 2006, 3, 25-31.

59. Hallquist, J. LS-Dyna Theory Manual, March 2006; Livermore Software Technology Corporation (LSTC): Livermore, CA, USA, 2012.

60. LSTC. Keyword User's Manual Volume II; Livermore Software Technology Corporation (LSTC): Livermore, CA, USA, 2007.

61. Cowper, G.R.; Symonds, P.S.; United States Office of Naval Research; Brown University Division of Applied Mathematics. Strain-Hardening and Strain-Rate Effects in the Impact Loading of Cantilever Beams; Brown University: Providence, RI, USA, 1957.

62. Jones, N. Structural Impact; Cambridge University Press: Cambridge, UK, 2011.

63. Momeni, M. Damage Evaluation of Steel Beam-Columns Subjected to Impulsive Loads Using Reliability Approach. Ph.D. Thesis, Shiraz University of Technology, Shiraz, Iran, 2021. (In Persian)

64. Rackauskaite, E.; Kotsovinos, P.; Rein, G. Model parameter sensitivity and benchmarking of the explicit dynamic solver of LS-DYNA for structural analysis in case of fire. Fire Saf. J. 2017, 90, 123-138. [CrossRef]

65. FEMA 426: Reference Manual to Mitigate Potential Terrorist Attacks against Buildings—Buildings and Infrastructure Protection Series; U.S. Department of Homeland Security: Washington, DC, USA, 2003.

66. Karlos, V.; Solomos, G. Calculation of Blast Loads for Application to Structural Components; European Commission's science and knowledge service, Joint Research Centre: Ispra, Italy, 2013.

67. U.S. DoD. Structures to Resist the Effects of Accidental Explosions; UFC 3-340-02; U.S. DoD: Washington, DC, USA, 2008.

68. Beshara, F. Modelling of blast loading on aboveground structures-I. General phenomenology and external blast. Comput. Struct. 1994, 51, 585-596. [CrossRef]

69. Suppressive Shields Structural Design and Analysis Handbook; US Army Corps of Engineers, Huntsville Division: Huntsville, AL, USA, 1977; HNDM-1110-1-2.

70. Krauthammer, T. Blast Effects and Related Threats; Pennsylvania State University: State College, PA, USA, 1999. 
71. Ruggieri, S.; Porco, F.; Uva, G.; Vamvatsikos, D. Two frugal options to assess class fragility and seismic safety for low-rise. Bull. Earthq. Eng. 2021, 19, 1415-1439. [CrossRef]

72. Miranda, E.; Reyes, C.J. Approximate lateral drift demands in multistory buildings with nonuniform stiffness. J. Struct. Eng. 2002, 128, 840-849. [CrossRef]

73. Campidelli, M.; Tait, M.; El-Dakhakhni, W.; Mekky, W. Inference of blast wavefront parameter uncertainty for probabilistic risk assessment. J. Struct. Eng. 2015, 141, 04015062. [CrossRef]

74. Asprone, D.; Jalayer, F.; Prota, A.; Manfredi, G. Proposal of a probabilistic model for multi-hazard risk assessment of structures in seismic zones subjected to blast for the limit state of collapse. Struct. Saf. 2010, 32, 25-34. [CrossRef]

75. Netherton, M.D.; Stewart, M.G. The effects of explosive blast load variability on safety hazard and damage risks for monolithic window glazing. Int. J. Impact Eng. 2009, 36, 1346-1354. [CrossRef]

76. Olmati, P.; Vamvatsikos, D.; Stewart, M.G. Safety factor for structural elements subjected to impulsive blast loads. Int. J. Impact Eng. 2017, 106, 249-258. [CrossRef]

77. Stewart, M.; Netherton, M.; Shi, Y.; Grant, M.; Mueller, J. Probabilistic terrorism risk assessment and risk acceptability for infrastructure protection. Aust. J. Struct. Eng. 2012, 13, 1-17. [CrossRef]

78. Stewart, M.G. Reliability-based load factor design model for explosive blast loading. Struct. Saf. 2018, 71, 13-23. [CrossRef]

79. Stewart, M.G.; Mueller, J. Terror, Security, and Money: Balancing the Risks, Benefits, and Costs of Critical Infrastructure Protection. In Proceedings of the Reliability Engineering Computing REC 2012, Brno, Czech Republic, June 2012; pp. 513-533.

80. Bartlett, F.; Dexter, R.; Graeser, M.; Jelinek, J.; Schmidt, B.; Galambos, T. Updating Standard Shape Material Properties Database for Design and Reliability (k-Area 4); Technical Report for American Institute of Steel Construction; American Institute of Steel Construction: Chicago, IL, USA, 2001.

81. Hadianfard, M.; Razani, R. Effects of semi-rigid behavior of connections in the reliability of steel frames. Struct. Saf. 2003, 25, 123-138. [CrossRef]

82. Thai, H.-T.; Uy, B.; Kang, W.-H.; Hicks, S. System reliability evaluation of steel frames with semi-rigid connections. J. Constr. Steel Res. 2016, 121, 29-39. [CrossRef]

83. Rubinstein, R. Simulation and the Monte Carlo Method; John Wiley\&Sons: New York, NY, USA, 1981.

84. Melchers, R.E.; Beck, A.T. Structural Reliability: Analysis and Prediction; John Wiley \& Sons Ltd.: Chichester, UK, 2018.

85. Broding, W.; Diederich, F.; Parker, P. Structural optimization and design based on a reliability design criterion. J. Spacecr. Rocket. 1964, 1, 56-61. [CrossRef]

86. Lees, F. Lees' Loss Prevention in the Process Industries: Explosion; Butterworth-Heinemann: Oxford, UK, 2012.

87. UNEP Industry and Environment Programme Activity Centre. Paris, FR. Hazard Identification and Evaluation in a Local Community; UNEP Industry and Environment Programme Activity Centre: Paris, France, 1992; Volume 12.

88. Center for Chemical Process Safety. Guidelines for Chemical Process Quantitative Risk Analysis; Center for Chemical Process Safety of the American Institute of Chemical: New York, NY, USA, 2000.

89. Hadianfard, M.A.; Shekari, M. An Equivalent Single-Degree-of-Freedom System to Estimate Nonlinear Response of Semi-fixed Flexural Members Under Impact Load. Iran. J. Sci. Technol. Trans. Civ. Eng. 2019, 43, 343-355. [CrossRef] 